\title{
Development of the Integrated Biomass Supply Analysis and Logistics Model (IBSAL)
}

\section{March 2008}

\section{Prepared by}

Shahab Sokhansanj, Anthony Turhollow, Erin Wilkerson

Oak Ridge National Laboratory

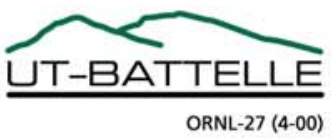




\section{DOCUMENT AVAILABILITY}

Reports produced after January 1, 1996, are generally available free via the U.S. Department of Energy (DOE) Information Bridge.

Web site http://www.osti.gov/bridge

Reports produced before January 1, 1996, may be purchased by members of the public from the following source.

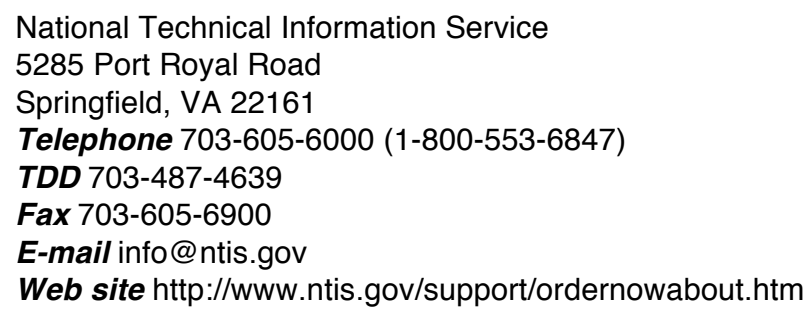

Reports are available to DOE employees, DOE contractors, Energy Technology Data Exchange (ETDE) representatives, and International Nuclear Information System (INIS) representatives from the following source.

Office of Scientific and Technical Information

P.O. Box 62

Oak Ridge, TN 37831

Telephone 865-576-8401

Fax 865-576-5728

E-mail reports@osti.gov

Web site http://www.osti.gov/contact.html

This report was prepared as an account of work sponsored by an agency of the United States Government. Neither the United States Government nor any agency thereof, nor any of their employees, makes any warranty, express or implied, or assumes any legal liability or responsibility for the accuracy, completeness, or usefulness of any information, apparatus, product, or process disclosed, or represents that its use would not infringe privately owned rights. Reference herein to any specific commercial product, process, or service by trade name, trademark, manufacturer, or otherwise, does not necessarily constitute or imply its endorsement, recommendation, or favoring by the United States Government or any agency thereof. The views and opinions of authors expressed herein do not necessarily state or reflect those of the United States Government or any agency thereof. 


\title{
DEVELOPMENT OF THE INTEGRATED BIOMASS SUPPLY ANALYSIS AND LOGISTICS MODEL (IBSAL)
}

\author{
Shahab Sokhansanj, Anthony Turhollow, Erin Wilkerson
}

March 2008

Prepared by

OAK RIDGE NATIONAL LABORATORY

Oak Ridge, Tennessee 37831-6283

Managed by

UT-BATTELLE, LLC

for the

U.S. DEPARTMENT OF ENERGY

under contract DE-AC05-00OR22725 



\section{CONTENTS}

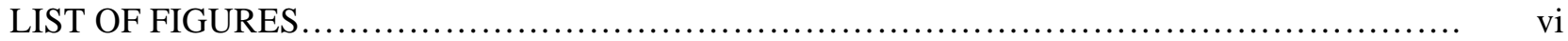

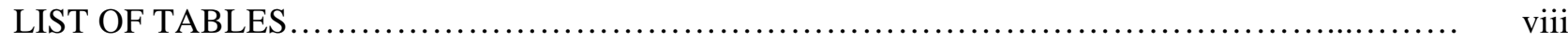

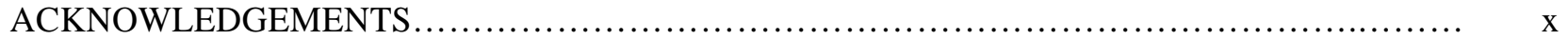

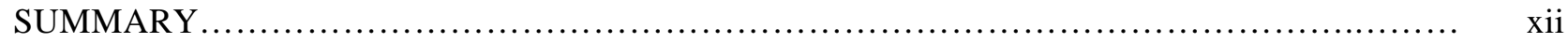

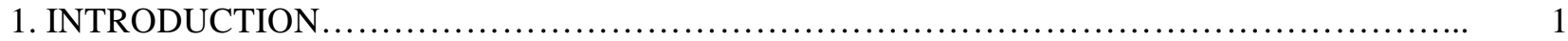

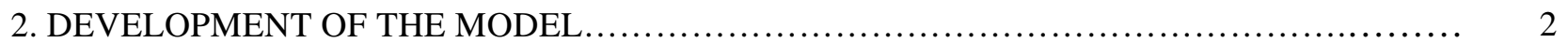

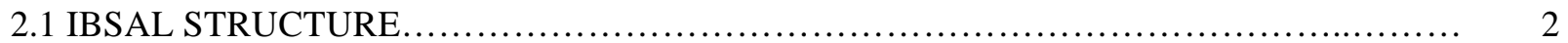

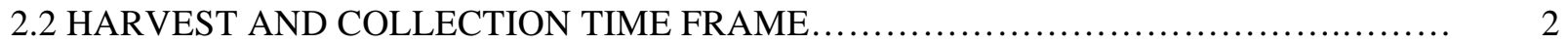

2.3 MOISTURE CONTENT OF BIOMASS AT THE TIME OF HARVEST $\ldots \ldots \ldots \ldots \ldots \ldots \ldots \ldots . \ldots$

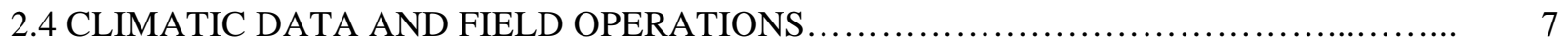

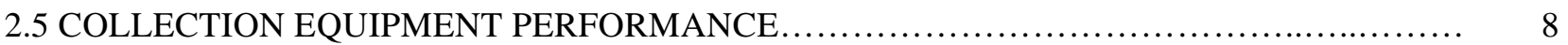

2.5.1 Sensitivity of Equipment Forward Speed to Yield ................................. 10

2.5.2 Sensitivity of Field Efficiency to Yield ......................................... 11

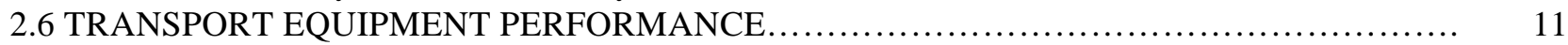

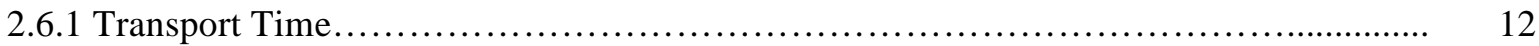

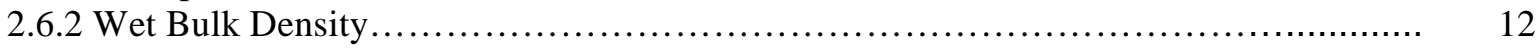

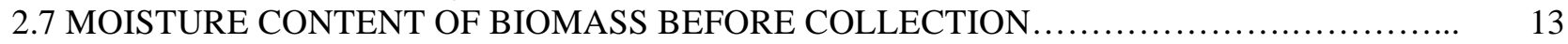

2.7.1 Transient Moisture Sorption Processes...................................... 13

2.7.2 Equilibrium Moisture and Relative Humidity................................... 14

2.7.3 Moisture Evaporation...................................................... 15

2.7.4 Numerical Solution to Transient Moisture Sorption Equations..................... 16

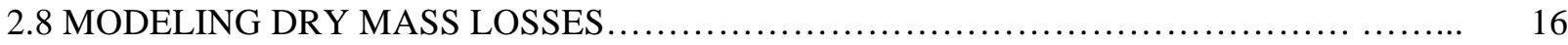

2.8.1 Modeling Dry Matter Loss in Queue........................................ 17

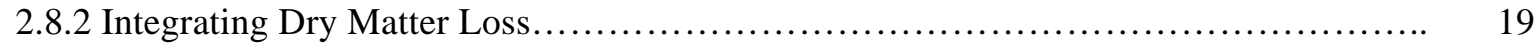

2.8.3 Dry Matter Loss in a Workstation............................................... 20

2.8 .4 Net Yield .................................................................... 23

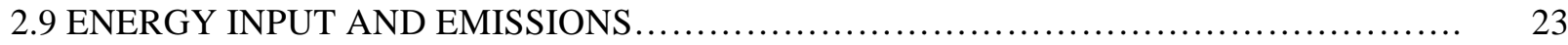

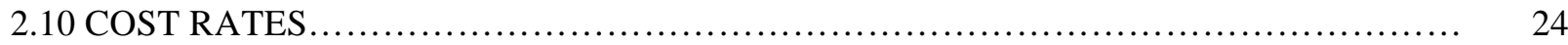

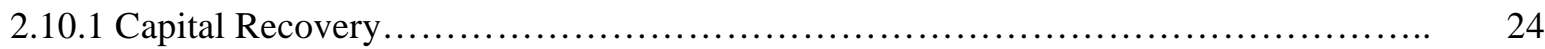

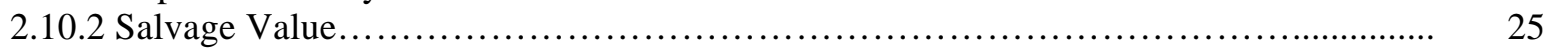

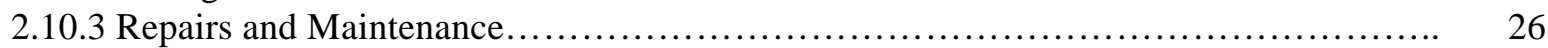

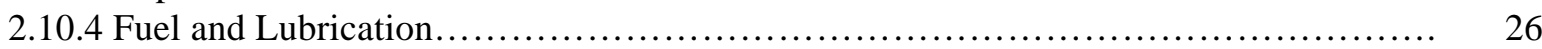

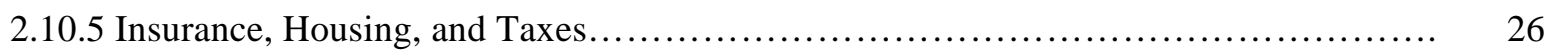

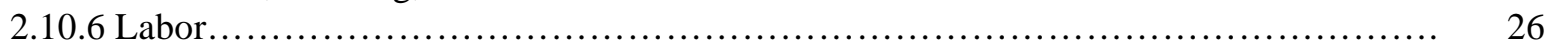

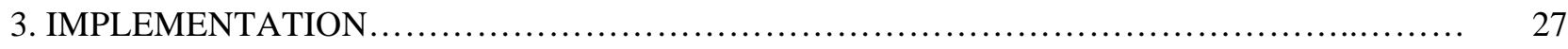

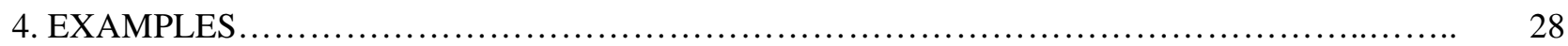

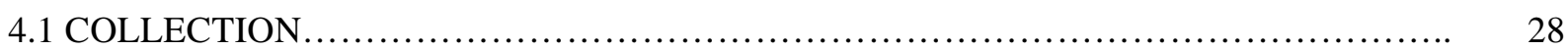

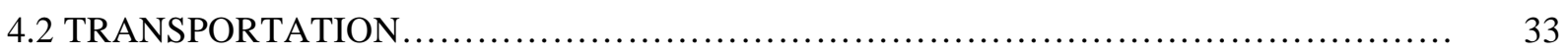

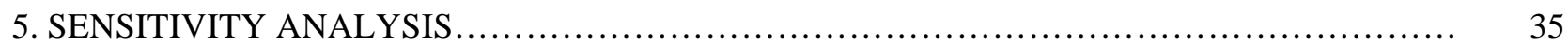

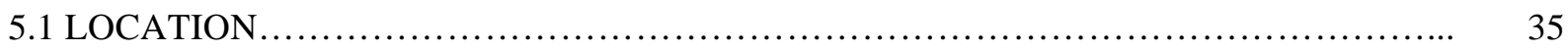

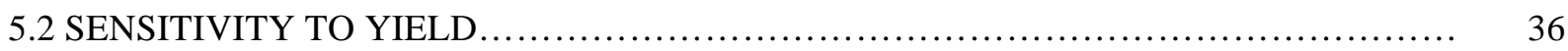

5.3 SENSITIVITY TO INITIAL HARVEST MOISTURE CONTENT ........................ 36

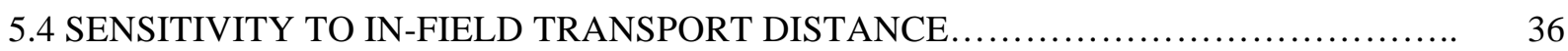

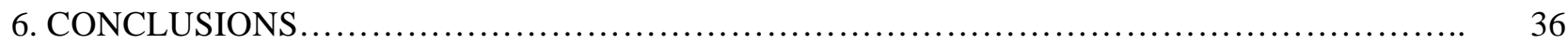

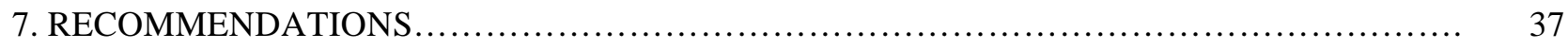




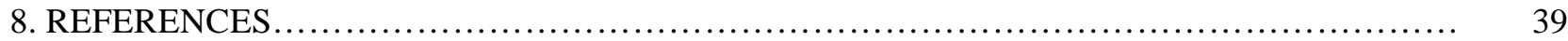

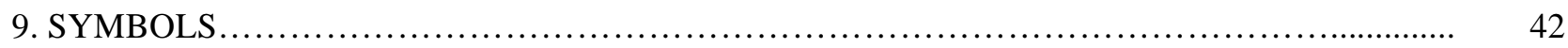

APPENDIX A List and specifications and cost of equipment and storage used in modeling stover 44

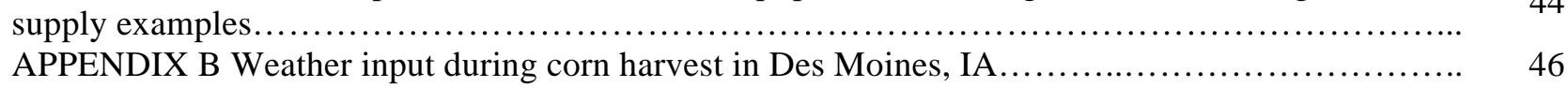

APPENDIX C Extracting weather data from TMY2 data 47

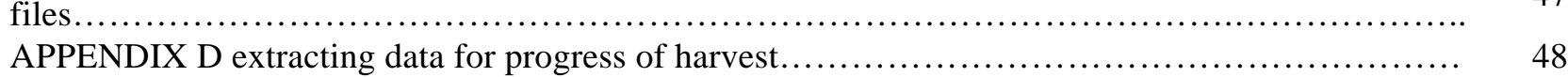

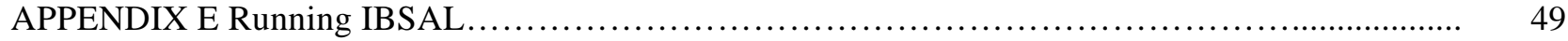



1 Overall structure of the IBSAL model...

2 Cumulative corn grain harvest progress of several corn growing states. Data

extracted from http://www.nass.usda.gov

$3 \quad$ Moisture content of corn grain and stalks after grain maturity date................ 6

$4 \quad$ Moisture content of stalks vs. moisture content of grain.........................

$5 \quad$ A typical daily average air-dry bulb temperature and rainfall for Des Moines, IA

6 Dry matter loss in the field while in a queue followed by dry matter loss at a workstation (machine operation).

7 Dry matter loss for a rake operating on a crop at various moisture contents and dry matter yields.

Flow diagram for discrete modeling of biomass collection operations. For transport, the model is similar except there are no weather delays.

An image of IBSAL with operations for shredding, baling, stacking chained to form a stover harvest assembly....

10 An image of IBSAL with operations for transporting bales from distributed storage (stack) sites to a biorefinery where the bales are restacked on a paved yard.

Sensitivity of cost of biomass collection and the quantity of biomass collected to several variables. 



\section{LIST OF TABLES}

Table

Page

1 Weekly progress of harvest (percent of the crop harvested for grain) for major corn growing states............................................... 4

2 Comparing equation 4 for estimating corn stalk moisture content from grain moisture content to the data of Sinners and Binversie (2004).................. 7

3 Speed and efficiencies of field equipment that are influenced by yield........... 10

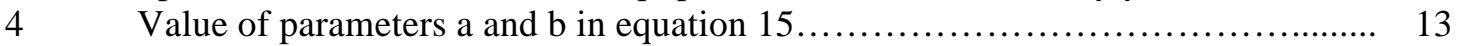

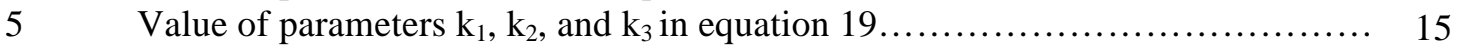

$6 \quad$ Moisture content ranges and dry matter losses in stored stover over a period of 9 months.... 17

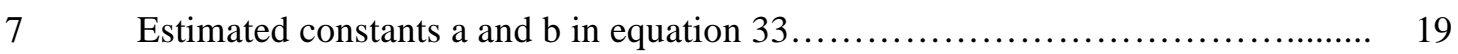

8 Suggested multiplier factors for use in predicting dry matter loss while biomass is in a queue ................................................................ $\quad 20$

9 Summary of mass balances in a corn stover harvesting experiment............. 22

10 Stover collection efficiencies for several harvest equipment.................... 22

11 Estimates of dry matter losses during various field operations.................. 23

12 Coefficients for the ASAE remaining value equations......................... 25

13 Five year average (2002-2006) of progress of corn grain harvest in Iowa.......... 29

14 List of input parameters related to simulation of collecting stover using the IBSAL model..................................................... $\quad 30$

15 Summary of the cost of harvesting, wrapping, and stacking stover bales ............ 31

16 Summary of other useful output of IBSAL for harvesting, wrapping, and stacking stover bales................................................. 32

17 Input to the IBSAL transportation example.............................. 33

18 IBSAL output for transporting biomass from distributed storage sites to a biorefinery 



\section{ACKNOWLEDGEMENTS}

This research was sponsored by the U.S. Department of Energy Office of Energy Efficiency and Renewable Energy, Office of the Biomass Program under contract DE-AC05-00OR22725 with UT Battelle, LLC. UT Battelle manages Oak Ridge National Laboratory for the Department of Energy.

The work benefited from consultation with and input from the following colleagues: Bob Perlack, Mark Downing, Jonathan Mielenz, Robin Graham, Lynn Wright, Janet Cushman, Richard Hess, Reed Hoskinson, Chris Wright, Corey Radtke, Kevin Kenney, Lester Pordesimo, Alvin Womac, C. Igathinathane, Mike Montross, John Cundiff, Amit Kumar, Peter Hausmanis, Sam Tagore, Lyle Stephens, Sudhagar Mani, Amit Kumar, and Tom Miles. 



\section{SUMMARY}

The Integrated Biomass Supply Analysis and Logistics (IBSAL) model was developed to simulate biomass supply chains from the field to the biorefinery. The model, written in Extend (www.imaginethatinc.com), consists of a network of operational modules threaded into a complete supply system. Each module contains mathematical equations to describe a process or event. The process modules are drying, wetting, and dry matter loss. The events are operations such as baling, loading, transporting, stacking, grinding, and storing. Modules interact with an external Excel spreadsheet to receive input data and write output data. Biomass flows from one module to the next through a connector. To date, 46 modules have been developed. Additional modules to simulate advanced harvesting operations and new biomass feedstocks are planned.

This technical memorandum presents the foundations of the IBSAL model, including detailed descriptions of the logic and mathematical equations used to calculate dry matter, fixed and operating costs, energy input to the system, and carbon emissions of powered equipment. Daily weather data is used by the model to determine field delays due to poor working conditions and their subsequent effect on feedstock collection costs. A unique feature of IBSAL is the yield-based adjustments that are made in estimating field speed and field efficiency. For a specific piece of equipment, productivity is adjusted based on deviance from the published reference value obtained for the machine for a particular biomass yield. Machine productivity drops at yields larger or smaller than the specified yield.

This report provides a detailed example of collecting and transporting 850,000 dry tons (dt) of biomass (stover) to a biorefinery in Iowa. The sequence of operations for collecting stover were combining grain, shredding/windrowing stover, baling stover in large square bales, wrapping bales in plastic tubes, and storing bales on the side of the farm. The bales were gradually trucked to a biorefinery over the entire year (350 days). The travel distance from storage sites to the biorefinery varied from 1 to 100 miles. The timing of corn harvest was determined using USDA crop progress data for Iowa. Daily weather data for Des Moines, IA were used. A corn grain yield of $185 \mathrm{bu} / \mathrm{ac}$ was assumed. The minimum number of equipment required for this particular scenario was estimated to be 150 combines, 65 shredders, 110 balers, 26 automatic bale collectors (Stinger), 40 bale loaders, 40 bale wrappers, and 175 tractors (to pull balers and shredders). For transport of bales from field sites to biorefinery, 30 loaders and 240 trucks were needed. The total investment, including preparation of ground for storage, was $\$ 100,110,885$. The total equipment purchase cost was $\$ 37,816,530$. The annualized cost of biomass delivered was $\$ 40.15 /$ dry ton (dt) (see Table 15). Feedstock costs can be significantly affected by dry matter loss during storage or by equipment. Initially 1,451,665 dt was available for harvest (4.38 dt/ac). At the conclusion of the harvest, 848,027 $\mathrm{dt}$, or roughly $58 \%$, of the original biomass remained in storage $(2.58 \mathrm{dt} / \mathrm{ac})$. Out of the total dry mass lost, 224,341 dt was attributed to storage (queue) and 376,345 dt to machine operations. IBSAL was also used to estimate fuel usage and carbon emissions of power equipment used in collecting and transporting the biomass. Roughly 435,000 and 1,509,000 Btu equivalent energy was input per dt collected and transported, respectively (2.9\% and $10 \%$ of the energy content of delivered biomass).

Recommendations for improving the accuracy and applicability of IBSAL are outlined at the end of this report: (1) calibration of moisture content and dry matter loss functions for various stages of biomass harvest, climatic conditions, and biomass species; (2) calibration of drying rate functions for biomass at different stages of handling; (3) updating relationships between efficiency and forward speed of machines with crop density (yield); (4) development of data on progress of harvest for additional biomass crops; (5) incorporating improved estimations of bulk density as a function of particle size, moisture content, and degree of compaction; and (6) improving relationships between power input, throughput capacity, and particle size for size reduction operations. 



\section{INTRODUCTION}

A successful biorefinery must have access to an adequate supply of low cost biomass with desirable characteristics throughout the life of the biorefinery. The orderly flow of biomass from the field to the point of conversion involves many highly inter-related processing steps. Each process affects the preceding operations as well as the operations that follow. System integration assembles the operational performance of an entire supply chain addressing the seasonal nature of biomass supplies and the complex interactions that must occur between producers, processors, transporters, and the local community. A coherent, economically viable biomass supply infrastructure can then be designed by optimizing a diverse thread of harvesting, storage, preprocessing, and transportation options that are specific to a biorefinery enterprise.

Feedstock supply system analysis addresses two major technical barriers as outlined in the Roadmap for Agricultural Biomass Feedstock Supply in the United States (DOE 2003): (1) uncertainty and risks associated with availability of adequate biomass supply to a biorefinery and (2) uncertainty in success and the high costs associated with the development of new equipment and supply infrastructure. These risks and uncertainties can be addressed by explicitly accounting for actual yield (yield minus an allowance for soil fertility and soil conservation), impacts of climate on the supply system, safety and environmental implications, and accurate cost information. An integrated analysis of the entire supply chain will identify the potential bottlenecks that must be alleviated before major investment in a biorefinery is made.

The Integrated Biomass Supply Analysis \& Logistics (IBSAL) model was developed at ORNL as a tool for analyzing biomass feedstock supply systems. The model simulates the flow of biomass through collection, transport, storage, and preprocessing and estimates energy consumption and costs. The model identifies the potential incremental improvements at every step of the supply chain (optimum designs) and critical improvements for the integration of the entire feedstock supply infrastructure (logistics). Other industries have developed very sophisticated systems analysis techniques to help make their industries competitive. Similarly, the IBSAL model takes advantage of innovative biomass supply options and logistical arrangements to help make the emerging bioindustry a viable enterprise.

The development of IBSAL has consisted of four stages: (1) establishing a framework for the model, (2) identifying factors and functional relations to be included in the model, (3) programming, and (4) validating the model with experimental and field data. To establish the IBSAL framework, flow charts are created to represent the movement of biomass through the supply chain. The supply chain includes all operations from harvest to delivery at the biorefinery. After the simulation framework is developed, each operation or process is mathematically modeled based on experimental relationships obtained from research literature or from industry standards. Using these mathematical models, modules are programmed in Extend to represent each supply chain operation or process. To complete an IBSAL simulation, appropriate modules are selected and chained together. [The model is written in Extend v6 (Extend 2003) (www.imaginethatinc.com), an object oriented high-level simulation language]http://. IBSAL was written to interface with an Excel spreadsheet for data input and output. Validation of IBSAL simulations using independent field data will proceed following complete verification and documentation of the model code. This technical memorandum describes the IBSAL framework and equations used to model supply chain operations. Future technical memorandums will provide detailed results of IBSAL validation and applications. 


\section{DEVELOPMENT OF THE MODEL}

The IBSAL model is a simulation framework for biomass supply chains. It consists of a network of operational modules that can be connected to form a complete biomass supply chain. Each module represents an operation or a process (e.g. grain combining, swathing, baling, loading a truck, truck travel, stacking, grinding, sizing, storing). Modules may also be processes such as drying, wetting, and chemical reactions such as fermentation and breakdown of carbohydrates leading to dry matter loss. Costing and energy calculations common to all operations are gathered into individual modules as well. Each module is independently constructed with a set of inputs and outputs. Modules may also interact with an external Excel file to receive data from or print data to worksheets. Biomass moves from one module to the next through a connector.

To begin a simulation, the user defines logistical features of the supply chain, such as number of farms involved, average yield, the start and progress of harvest, and the moisture content of the biomass. The model also requires daily weather data including air temperature, relative humidity, wind speed, rainfall, and snowfall. An Excel spreadsheet containing equipment specifications provides data for calculating service time. This information is used in calculating drying and wetting of the biomass and workability of the soil. The user also defines the safe moisture content for baling and minimum temperature below which working on the field should cease. Once all input parameters are identified, the model calculates cost per dry ton (dt) of biomass, energy input to power equipment, and carbon emissions from power equipment.

The biomass collection and supply system is divided into two activities: (1) collection and storage of biomass, and (2) preprocessing and transportation of biomass from collection sites to a biorefinery. The collection processes start immediately following the grain harvest or wilting of the grass in the field. The model execution is fast and usually does not take more than 30 seconds to complete a run. The model is highly interactive allowing changes to inputs and observing the output as the program executes.

In the following subsections, the construct of the model is briefly described along with the inputs and outputs of the model. Subsequent sections present examples of applying the IBSAL model to simulate several biomass supply option.

\subsection{IBSAL STRUCTURE}

Figure 1 is a block diagram of the main components of the IBSAL model. Inputs to the model are summarized in the left blocks and outputs from the model are summarized in the right blocks. The central blocks represent the assembly of operations that simulate the flow of biomass from field to storage. Default values for input data are contained in the Excel input file. The equations representing operations are the core of the program. These equations can be modified or new ones can be added if a user has access to the code. All variable input data can be entered in the program via the Excel worksheets. Generally there is no need to change the model unless better equations describing the processes or more specific data related to a crop or a machine become available.

\subsection{HARVEST AND COLLECTION TIME FRAME}

The commencement of grass or grain harvest depends upon local climate conditions and biomass moisture content. Farmers prefer to complete harvest as quickly as possible to allow time for preparing the land for the following season, to prepare for harvest of the next crop, or to minimize the potential of work stoppage due to cold, humid, or freezing conditions. Harvest operations may 
continue until cool temperatures or precipitation makes field operations difficult. For most of the midwestern U.S., harvest begins around the first week of August and ends in late October or mid November. For herbaceous biomass, weather permitting, the harvest may continue through winter and the following spring.

The National Agricultural Statistics Service of the U.S. Department of Agriculture publishes a report of weekly progress for a number of major crops during the growing season. The data is available at http://www.nass.usda.gov. Maturity dates and the weekly harvest progress for many important crops can be found on the "U.S. and State Data" link by "crops" from the dropdown menu.

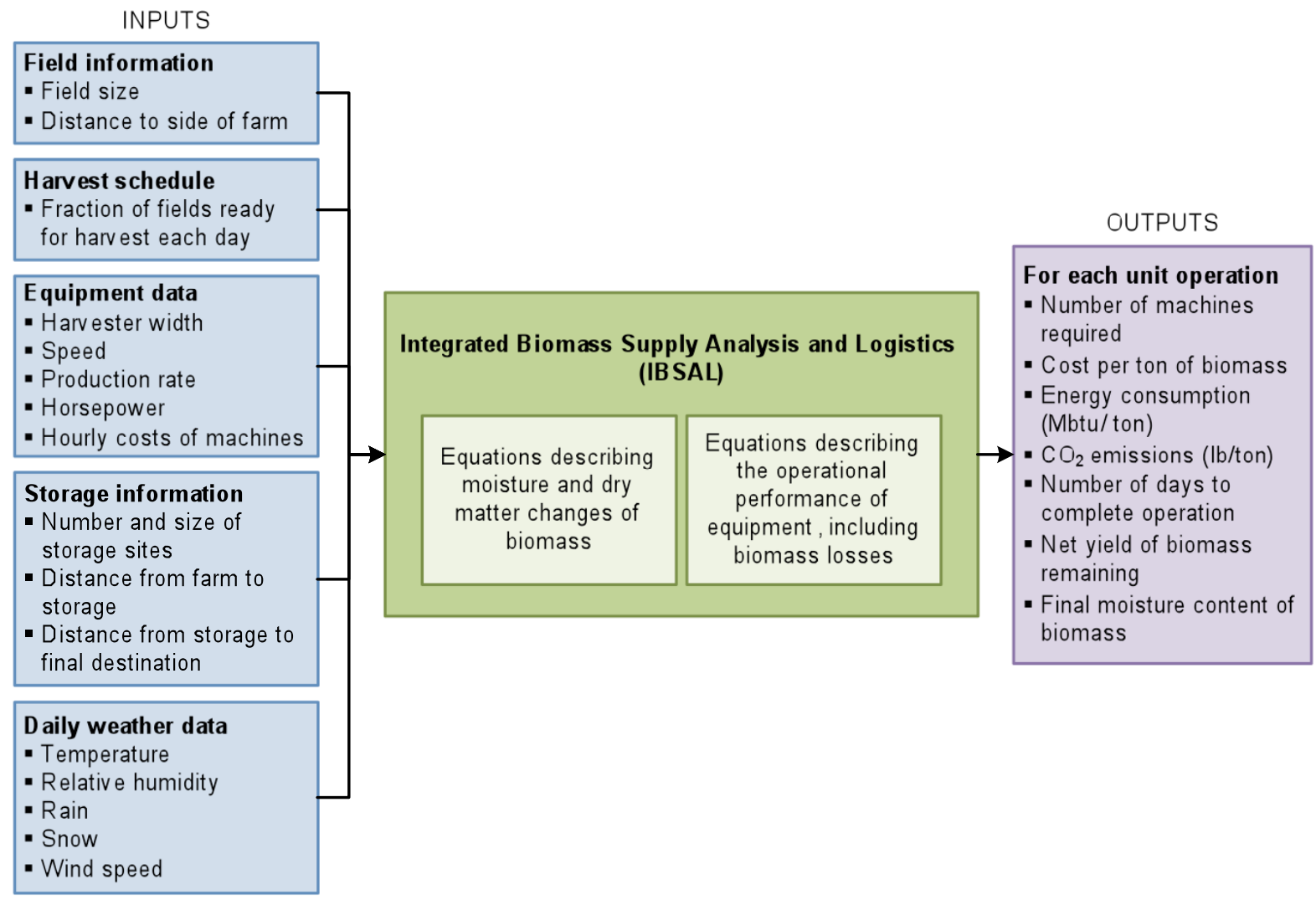

Figure 1. Overall structure of the IBSAL model

The data on the length of the corn grain harvest period and harvest progress for each state can be downloaded from http://www.nass.usda.gov/. The weekly data consists of the cumulative percentage of units (or quantities) of corn harvested between week 36 and week 45 (Table 1, Figure 2). The percentage harvested for warmer regions starts high in week 36 whereas the percentage harvested for colder regions starts low in week 36. Similarly the final percentage of harvested grain is high at the end of harvest season (week 45), but the final percent harvested grain for cold region is less than $100 \%$ (Figure 2). The exact week of start of harvest for each state is not recorded. The final week generally lasts until week 47. 
Table 1. Weekly progress of corn harvest (percent of the crop harvested for grain) for major corn growing states

\begin{tabular}{rrrrrrrrr}
\hline $\begin{array}{c}\text { Week } \\
\text { number }\end{array}$ & \multicolumn{1}{c}{ KY } & \multicolumn{1}{c}{ IL } & NE & ND & OH & MI & IA & TX \\
\hline 36 & 26 & 4 & 4 & 0 & 0 & 0 & 2 & 63 \\
37 & 38 & 10 & 8 & 0 & 1 & 1 & 5 & 69 \\
38 & 53 & 21 & 14 & 2 & 4 & 3 & 9 & 77 \\
39 & 67 & 35 & 23 & 6 & 8 & 6 & 16 & 82 \\
40 & 81 & 51 & 32 & 15 & 16 & 11 & 25 & 87 \\
41 & 86 & 64 & 43 & 28 & 25 & 19 & 40 & 93 \\
42 & 90 & 77 & 57 & 47 & 37 & 31 & 58 & 96 \\
43 & 94 & 86 & 71 & 64 & 53 & 46 & 74 & 97 \\
44 & 97 & 93 & 82 & 76 & 72 & 61 & 86 & 99 \\
45 & 99 & 97 & 89 & 83 & 84 & 74 & 94 & 100 \\
\hline
\end{tabular}

Source http://www.nass.usda.gov
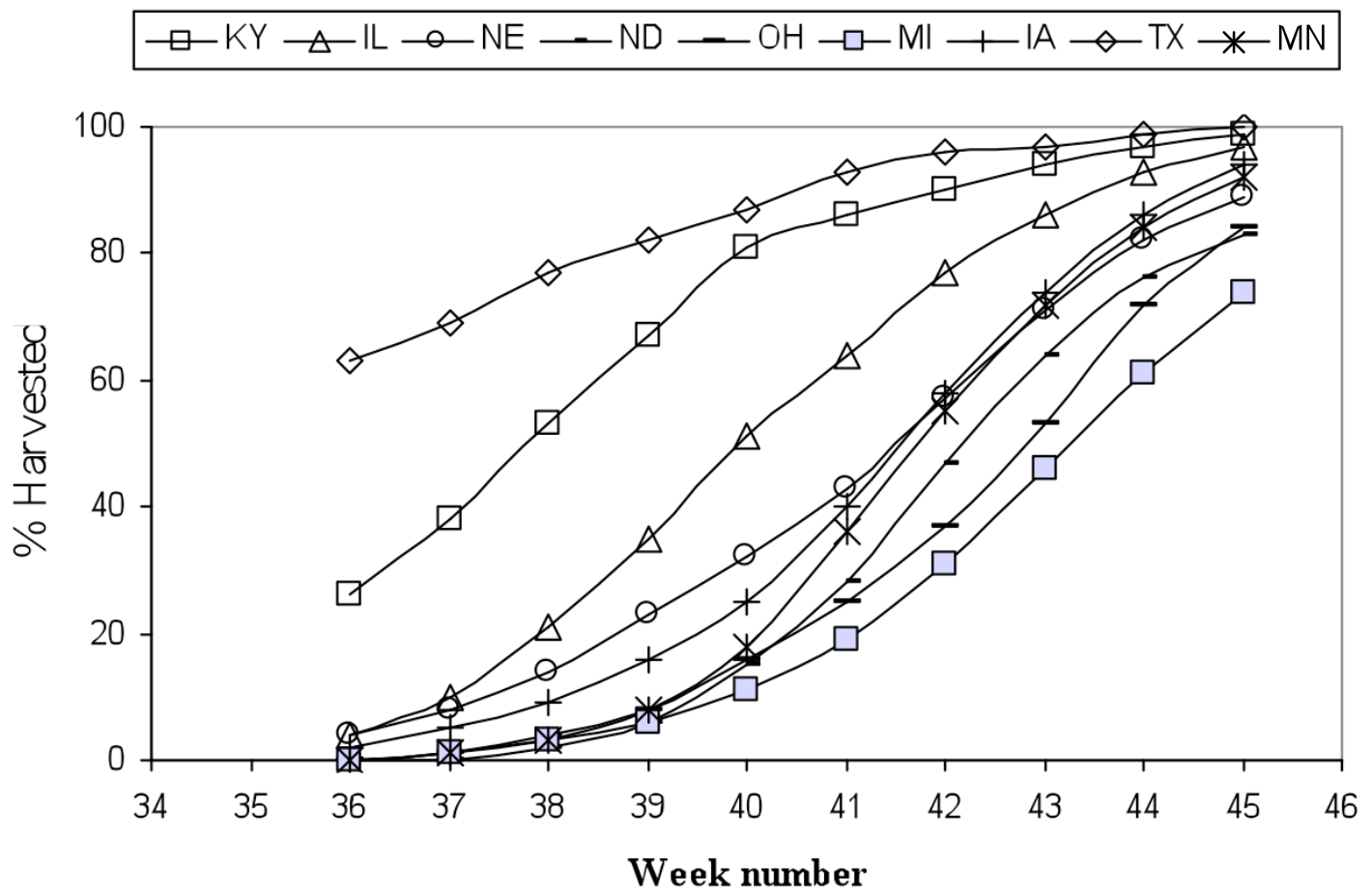

Figure 2. Cumulative corn grain harvest progress of several corn growing states. Data extracted from http://www.nass.usda.gov

IBSAL requires daily cumulative percent harvest that is calculated from weekly data using equation 1 ,

$P_{i}=\left(\frac{i}{7}\right) P_{j^{*}}, \quad j<\left(\frac{i}{7}\right)<j+1, P_{j^{*}}=$ Interpolate $\left[P_{j}, P_{j+1}{ }_{-}^{-}\right.$ 
$i=1$ to $365, j=1$ to 52

where $P_{i}=$ daily cumulative fraction of units harvested

$P_{j}=$ weekly cumulative fraction of units harvested

$P_{j^{*}}=$ interpolated weekly accumulated harvested stover

$i=$ day number

$j \quad=$ week number.

The daily number of items (in IBSAL a unit of land is called an item) ready for harvest is calculated from the difference between two consecutive days of cumulative harvest values,

$$
H_{i}=\left(N_{\text {Items }}\right)\left(P_{i}-P_{i-1}\right)
$$

where $H_{i}=$ daily number of items ready for harvest

$P_{i} \quad=$ cumulative harvested fraction on day $i$

$P_{i-1}=$ cumulative harvested fraction on day $i-1$

$N_{\text {items }}=$ total number of discrete items used in the discrete model.

The harvest progress for a state is arranged in two columns in the IBSAL Excel spreadsheet. Column 1 is the week number and column 2 is the cumulative harvest value (in decimal fraction). IBSAL copies the values of these columns in its input data set. See Appendix D for a brief procedure for extracting data from TMY and constructing the input file. A more detailed Users Guide for the IBSAL will be forthcoming.

\subsection{MOISTURE CONTENT OF BIOMASS AT THE TIME OF HARVEST}

Starting from an initial moisture content, IBSAL uses a dynamic moisture sorption routine to calculate daily moisture changes of the biomass during harvest operations. These drying and wetting equations will be described in Section 2.7. For stover, initial moisture content is estimated based on grain moisture content. Figure 3 plots the daily measurement of grain and biomass moisture contents during a harvest in Eastern Tennessee (Prodesimo et al. 2004). For this particular case, the initial moisture content of the stover stalks was about $72 \%$ [wet basis (wb)] when the grain moisture content was about $40 \%(\mathrm{wb})$. Moisture content of stalks and grain decreased gradually as the harvest season progressed. Towards the end of the harvest season, after 80 days, the moisture content of stover and grain were almost equal at about $10 \%$ (wb) (Figure 3).

Igathinathane et al. (2006) reported similar data when they compared the moisture content of grain to the average moisture content of sections of the standing corn stalks. The decrease in moisture content of grain was gradual, but the decrease in moisture content of stalks was initially slow and then decreased rapidly when the moisture content of grain dropped to less than $20 \%$ (wb). This drop in moisture content of stalk vs. the moisture content of grain is shown in Figure 4. Shinners and Binversie (2004) measured moisture content of stover and grain in Wisconsin. The average corn stalk moisture content was $73 \%$ (wb) when grain moisture content was $45 \%$ (wb) and the moisture content of stalk was $46 \%$ (wb) when the corn grain moisture content was $20 \%$ (wb). This reduction in moisture content was within 40 days of the start of the harvest season. Shinners and Binversie (2004) did not report data on moisture content of grain or stalks below the $20 \%$ (wb) moisture content grain and thus the sharp decrease in moisture content was not observed (or reported).

Figure 4 shows that the an exponential curve approximates moisture content of stalks vs. moisture content of grain, 
$M C_{S}=0.73 *\left(1-3.9451 e^{-18.8397 M C_{g}}\right), \quad M C_{g} \geq 0.08, \quad R^{2}=0.93$

where $M C_{s}=$ stalk moisture content (fraction decimal wb)

$M C_{g}=$ grain kernel moisture content (fraction decimal wb).

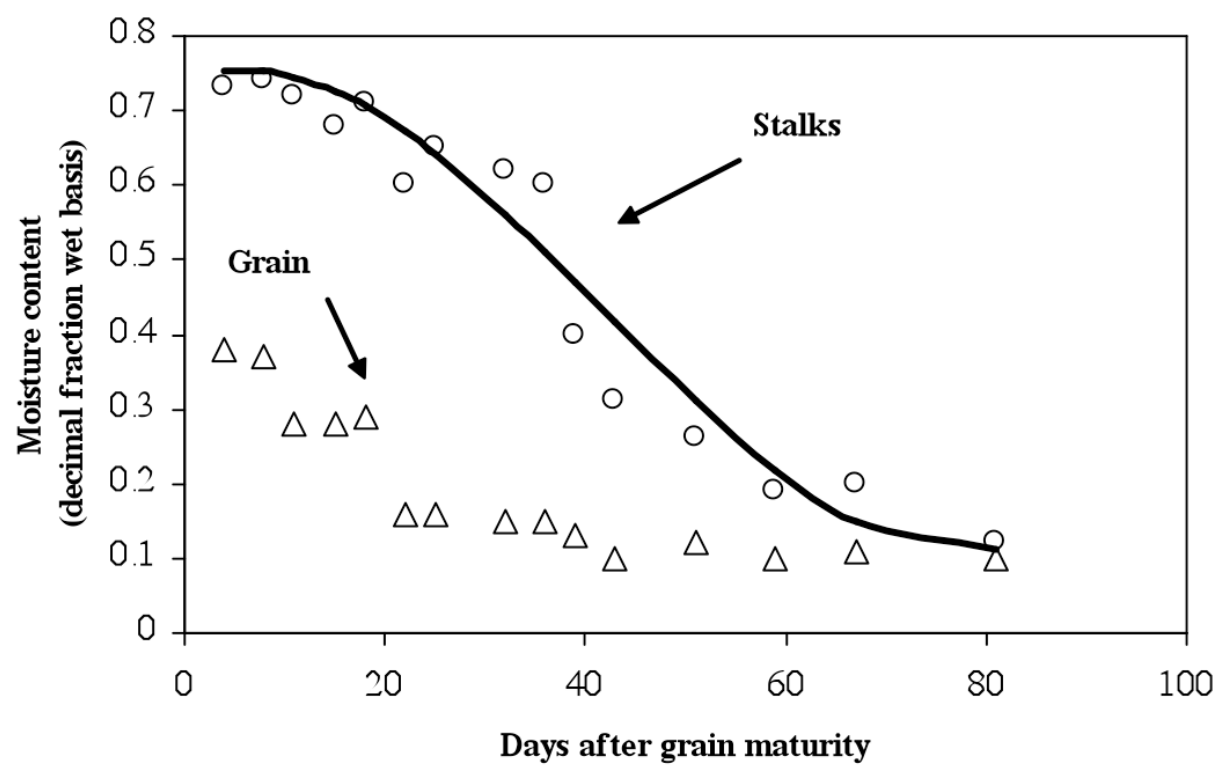

Figure 3. Moisture content of corn grain and stalks after grain maturity date (August 1)

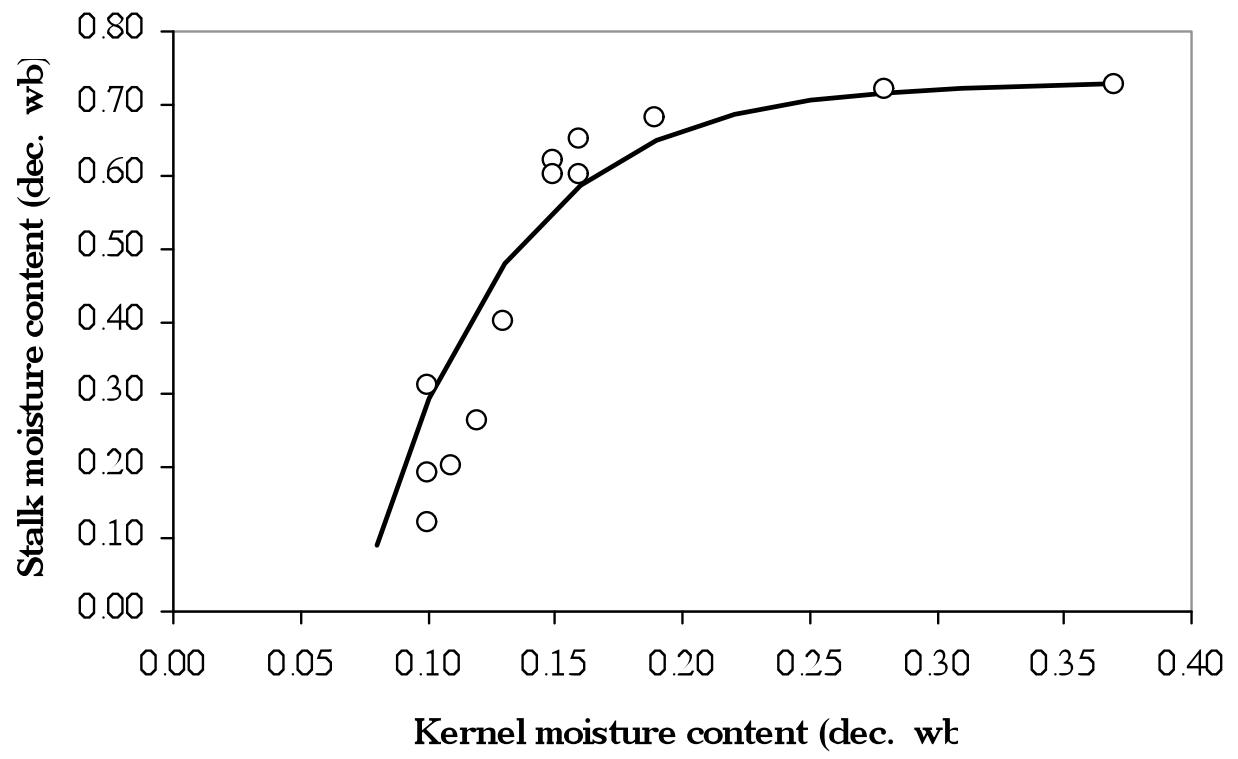

Figure 4. Moisture content of stalks vs. moisture content of grain 
IBSAL uses the following equation to approximate the moisture content of corn kernel as the grain harvest progresses daily,

$$
M C_{g}=M C_{g o}\left(1-P_{i}\right)+M_{e} P_{i}
$$

Where $M C_{g} \quad=$ moisture content of grain on day $i$

$M C_{g o} \quad=$ moisture content of grain at the start of harvest season

$P_{i} \quad=$ cumulative harvested fraction on day $i$

$M_{e} \quad=$ equilibrium moisture content of the grain (on the cob) on day $i$.

Equation 4 assumes the daily drop in moisture content of grain during the harvest season follows the cumulative fraction representing the harvest progress. Equation 4 ensures an asymptote to reach an equilibrium moisture content late in the harvest season. The equilibrium moisture content of the grain on the $\operatorname{cob} M_{e}$ is estimated from the equilibrium moisture content of the ear corn. ASAE D245.5 (ASABE 2006a) gives the following Modified Henderson equation,

$$
M_{e}=\frac{1}{100}\left[\frac{\ln (1-r h)}{-k_{1}\left(T+k_{2}\right)}\right]^{k_{3}}
$$

where $\quad r h=$ relative humidity (decimal fraction)

$T=$ ambient air temperature $\left({ }^{\circ} \mathrm{C}\right)$.

The coefficients for ear corn are $k_{1}=6.4424 \times 10^{-5}, k_{2}=22.15$, and $k_{3}=0.4795$. The ambient relative humidity $r h$ and temperature $T$ are input from the local weather data file discussed in section 2.4.

Note that equations 3-5 are specifically developed for corn grain and corn stalks and for a specific case in Eastern Tennessee. These equations may not be applicable to other corn growing locations. Table 2 shows that equation 4 estimated the 2002 data in Shinners and Binversie (2004) reasonably well, but the equation was not accurate in predicting their 2003 data.

Table 2. Comparing equation 4 for estimating corn stalk moisture content from grain moisture content to the data of Sinners and Binversie (2004)

\begin{tabular}{cccc}
\hline Grain moisture content & 2002 data & 2003 data & Equation 4 \\
\hline 0.40 & 0.75 & 0.73 & 0.75 \\
0.35 & 0.74 & 0.72 & 0.73 \\
0.30 & 0.72 & 0.65 & 0.71 \\
0.25 & 0.70 & 0.56 & 0.69 \\
0.20 & 0.67 & 0.46 & 0.67 \\
\hline
\end{tabular}

\subsection{CLIMATIC DATA AND FIELD OPERATIONS}

Weather elements such as rain, snow, frost, excessive soil moisture, and other weather-related factors affect the operation of field equipment that may result in delays in harvest and collection operations. ASAE D497.5 (ASABE 2006b) lists probabilities for a working day $(p W D)$ for soil working operations (tillage) and for traffic operations where a crop is processed and the soil needs to be dry enough to provide machine support. A single value of $p W D$ represents the probability of working days for the entire harvest season. The current model does not keep track of the moisture balance in the soil in order to make a decision on whether on a particular day the condition of the soil is suitable for machinery traffic. This feature will be added to the model in later editions. Currently, IBSAL reads a daily rainfall and snowfall and, if appropriate, delays field operations for a few hours as a direct function of the precipitation. 
The $p W D$ does not represent delays in operations such as delay in baling due to rain or snow. Rain and snow increases the moisture content of crop in the field for a short time. Collecting and baling this freshly wetted crop may cause heating and spoilage. A delay is required for the moisture content of the material to drop to a safe level for collection and baling. The calculation of this delay is demonstrated in section 2.7 where biomass drying equations are developed.

The weather data used in IBSAL is extracted from TMY2 (Typical Meteorological Year) (Marion and Urban 1995), which is accessible at http://rredc.nrel.gov/solar/old_data/nsrdb/tmy2/. TMY2 database contains hourly weather data sets for many cities for a typical year (estimated based on actual weather data from 1961-1980). The data is useful for evaluating operations in typical circumstances, not worst case scenarios. IBSAL requires daily weather values; therefore the TMY2 data must be converted to daily average dry bulb temperature $\left({ }^{\circ} \mathrm{C}\right)$, daily snowfall $(\mathrm{mm})$, daily average relative humidity (decimal), daily evaporation $(\mathrm{mm})$, and daily rainfall $(\mathrm{mm})$. Step-by-step instructions for extracting weather data from TMY2 are outlined in Appendix C. Temperature, relative humidity, and snowfall and rainfall values are read directly from TMY2. Daily evaporation was calculated using a pan evaporation formula that required temperature, relative humidity, and daily average wind speed (this equation will be discussed in Section 2.7). The input file is an Excel file with 365 lines of data. Other weather data files that contain the same data as those extracted from TMY2 can be used if such data is available.

Figure 5 shows the daily temperature and rainfall during the harvest season (August 1 to December 31 for Des Moines, Iowa). Daily temperatures during harvest season decreases steadily. Precipitation fluctuations follow temperature fluctuations. The current version of the program does not track the soil moisture content which determines the suitability of a soil to support harvest and transport equipment (Rotz and Harrigan, 2005). Instead, the program executes a delay function to represent a delay in an operation due to unsuitability of weather.

Previous researchers have used empirical observations to execute delays in harvest simulations. Nilsson (1999) assumed on days that rain occurs, the operation ceases after 1:00 pm. Montovani and Gibson (1992) considered days with a snow cover of 6 inches $(153 \mathrm{~mm})$ or more as non-working days. In the current IBSAL model, it is assumed that precipitation delays harvest for a specified period of time. One $\mathrm{mm}$ of rainfall causes one working hour delay. For example, a $10 \mathrm{~mm}$ rainfall delays a field operation by 10 hours. It is also assumed that one $\mathrm{mm}$ of snowfall delays a field operation by 2 hours. In IBSAL, a field operation (e.g. combining, raking, baling) is paused when the temperatures drop below a specified temperature. Examples in section 4 use $-20^{\circ} \mathrm{C}$. The operation resumes when warmer conditions prevail. This temperature and other weather-related delays are user specified inputs and can be varied by the user. In future versions of IBSAL, estimations of soil moisture content and criteria for working in the field after rainy or snowy periods will be developed.

\subsection{COLLECTION EQUIPMENT PERFORMANCE}

A workstation in IBSAL calculates the time it takes to perform an operation. For traveling field equipment whose performance depends on the width of cut and forward speed, the following equation is used (Hunt 1986, ASABE 2006c),

$$
\begin{aligned}
& t=\frac{8.25 A}{S w e}+t_{m} \\
& \text { where } A=\text { area (ac) } \\
& S \quad=\text { equipment speed (mph) } \\
& w \quad=\text { cut width (ft) }
\end{aligned}
$$


$e \quad=$ efficiency of equipment (fraction decimal)

$t=$ time for the operation to be completed (hr)

$t_{m}=$ time in field on operations besides traveling (e.g. time to tie or wrap a bale) (hr).

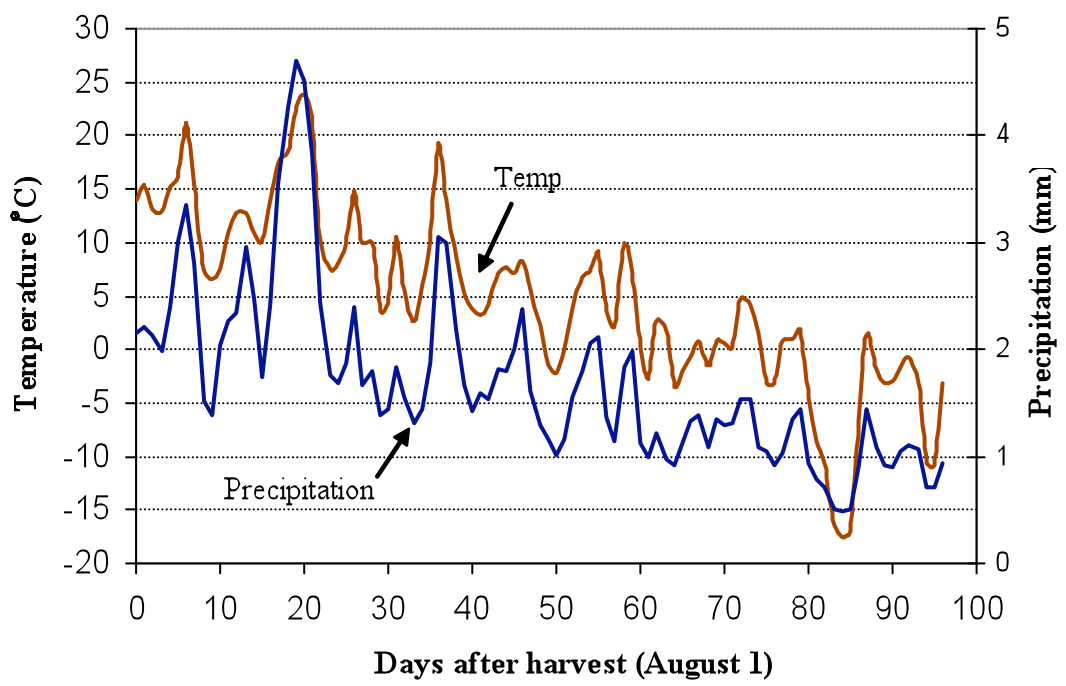

Figure 5. A typical daily average air-dry bulb temperature and rainfall for Des Moines, IA.

ASAE Standard D497.5 (ASABE 2006b) provides estimates of performance data for agricultural equipment. Field efficiency is the ratio between the productivity of a machine under field conditions and the theoretical maximum productivity. According to ASAE EP496.3 (ASABE 2006c) "Field efficiency accounts for failure to utilize the theoretical operating width of the machine; time lost because of operator capability and habits and operating policy; and field characteristics. Travel to and from a field, major repairs, preventive maintenance, and daily service activities are not included in field time or field efficiency. Field efficiency is not a constant for a particular machine, but varies with the size and shape of the field, pattern of field operation, crop yield, moisture, and crop conditions."

Table 3 is extracted from this published data for selected equipment where performance varies with speed. Efficiencies provided are measured in terms of time during which useful work is done over the total time spent in the field. In some cases, speed varies widely which affects the field performance of the equipment. Crop yield (crop density) affects the speed of field equipment. Equipment operators may have to adjust field speed to maximize the performance of equipment. For example, for a baler to operate at its design capacity the operator increases the forward speed if the yield (crop density) is low and the operator reduces the forward speed if the crop density is high. Adjustment in speed and performance of field working equipment is formulated in section 2.5.1 sensitivity section. 
Table 3. Speed and efficiencies of field equipment that are influenced by yield

\begin{tabular}{lcccc}
\hline \multicolumn{1}{c}{ Equipment - operations } & $\begin{array}{c}\text { Speed } \\
\text { range (mph) }\end{array}$ & $\begin{array}{c}\text { Speed typical } \\
(\mathbf{m p h})\end{array}$ & $\begin{array}{c}\text { Efficiency, } \\
\text { range (\%) }\end{array}$ & $\begin{array}{c}\text { Efficiency, } \\
\text { typical (\%) }\end{array}$ \\
\hline Combine (self propelled) & $2-5$ & 3.0 & $60-75$ & 65 \\
Mower-conditioner & $3-6$ & 5.0 & $75-85$ & 80 \\
Shred & $5-12$ & 7.0 & $75-90$ & 80 \\
Rake & $4-8$ & 6.0 & $70-90$ & 80 \\
Baler - large squares & $4-8$ & 5.0 & $70-90$ & 75 \\
Baler - round & $3-8$ & 5.0 & $55-75$ & 65 \\
Forage harvester (sp) & $1.5-6.0$ & 3.5 & $60-85$ & 70 \\
Windrower (swather) & $3-8$ & 5.0 & $70-85$ & 80 \\
Loafer & $4-8$ & 5.0 & $60-70$ & 65 \\
\hline
\end{tabular}

${ }^{1}$ Loafer efficiency is assumed to be similar to the round baler efficiency ASAE D497.5 (ASABE 2006b)

For other processing equipment such as grinders, the service time at a workstation is calculated by

$$
t=\frac{Q}{q e}
$$

where $Q \quad=$ total tonnage to be processed $(\mathrm{dt})$

$q \quad=$ rated capacity or throughput $(\mathrm{dt} / \mathrm{hr})$

$e \quad=$ process efficiency (fraction decimal).

The rated capacity $q$ and process efficiency $e$ are taken either from published literature, consultation with manufacturers, or from performance testing of the equipment.

\subsubsection{Sensitivity of Equipment Forward Speed to Yield}

For a given equipment size (e.g. fixed width of cut), equation 6 states that the field speed $S$ and the field efficiency $e$ affect the time a process is completed. IBSAL makes two adjustments in its formulation of field equipment speed and field equipment efficiency. For speed, IBSAL follows the actual field practice where an operator adjusts the forward speed of equipment to compensate for deviation from an optimum density of the crop in the field. In other words, the operator reduces the speed if the yield of the crop is over the optimum operating capacity of the equipment. Likewise the operator increases the speed of the equipment if the yield of the crop is thinner than an optimal density for the equipment. The speed adjustment can be written in the form of the following equation,

$S=S_{b}\left(\frac{Y_{b}}{Y}\right)$

$$
\text { where } \begin{aligned}
S & =\text { adjusted speed }(\mathrm{mph}) \\
S_{b} & =\text { optimum speed for the optimum yield }(\mathrm{mph}) \\
Y & =\text { yield }(\mathrm{dt} / \mathrm{ac}) \\
Y_{b} & =\text { optimum yield or optimum yield }(\mathrm{dt} / \mathrm{ac}) .
\end{aligned}
$$

The limits to the range of speed calculated from equation 8 are the ranges published in ASAE D497.5 that are listed in Table 3. A machine of larger or smaller size needs to be selected for the operation in order to fall within the speed range. IBSAL adjusts the speed of equipment based on using a published optimum speed [ASAE EP497.5 (ASBAE 2003a)]. To estimate an optimum yield for a baler, the manufacturer's published or recommended yield $\mathrm{dt} / \mathrm{hr}$ is divided by the ac/hr. For other 
equipment, in the absence of field data at this time, best estimates are developed from consultations with experienced operators.

\subsubsection{Sensitivity of Field Efficiency to Yield}

For adjustment in efficiency $e$, IBSAL follows the work of Dr. Jenkins and his co-workers at University of California. Jenkins (2005) shows that the machine productivity reaches a maximum at an optimum yield. The productivity drops at yield larger or smaller than the optimum yield. IBSAL reflects this sensitivity of productivity to yield by adjusting the efficiency,

$$
e=e_{b}\left[1-\left(\frac{Y_{b}-Y}{Y_{b}}\right)^{2}\right]
$$

$$
\text { where } \begin{aligned}
e & =\operatorname{adjusted} \text { efficiency (fraction decimal or percent) } \\
e_{b} & =\text { optimum efficiency for the optimum yield (fraction decimal or percent) } \\
Y & =\text { yield }(\mathrm{dt} / \mathrm{ac}) \\
Y_{b} & =\text { optimum yield }(\mathrm{dt} / \mathrm{ac})
\end{aligned}
$$

Equation 9 states that yields larger or smaller than the optimum yield reduce the value of efficiency. Mathematically the value of yield $Y$ in equation 9 can not exceed more than twice the optimum yield $Y_{b}$. IBSAL uses the values for field equipment efficiency published in ASAE EP497.5 (ASABE 2006b) as $e_{b}$. For $Y_{b}$ IBSAL uses a similar approach to adjusting equipment forward speed.

\subsection{TRANSPORT EQUIPMENT PERFORMANCE}

Transport equipment is involved both in the field as well as transport on open roads. For transport in the field, transport time involves loading and unloading plus a transport time from the loading point(s) to the unloading point. The distance between the loading and unloading points is estimated from,

$$
L=\tau\left(x^{2}+y^{2}\right)^{/ 2}
$$

where $L \quad=$ transport distance (miles)

$x \quad=\mathrm{x}$-coordinate distance travel on the field to stacking area (miles)

$y \quad=\mathrm{y}$-coordinate distance travel on the field to stacking area (miles)

$\tau \quad=$ winding factor

The winding factor, $\tau$, represents deviation from a straight line. Its value depends on the geometry of a field, travel pattern for the transport equipment on the field, and roadways for the transport equipment on roads. Nilsson (1999) uses a value of 1.8 for transport of bales from field to a power plant in Sweden. In IBSAL, winding factor is a user defined variable. For examples in section 4, IBSAL assumes a value of $\tau=1.4$.

IBSAL calculates the transport time $t$ by dividing the distance over the average speed,

$$
t=\frac{L}{S_{T}}
$$

where $S_{T}=$ average speed of the transport equipment (mph). 


\subsubsection{Transport Time}

Transport time consists of travel time (loaded and empty) and can be presented as,

$t_{t r}=\frac{t_{f u l l}+t_{\text {empty }}}{e}$

where $t_{t r}=$ transport time per load (hr)

$t_{\text {full }}=$ travel time with load (hr)

$t_{\text {empty }}=$ travel time without load (hr)

$e \quad=$ transport efficiency (decimal fraction).

A value for $e$ (efficiency) is estimated from field and road conditions such as potential obstacles that would slow down the speed of the equipment. If not known, IBSAL uses a default value e $=1.0$. Time should also be allowed for loading and unloading operations. Loading equipment may be separate equipment (loaders) or an integral part of the transport equipment (auto stackers). The loading and unloading times are provided by manufacturers or taken from field observations. These times are assigned to loading and unloading equipment as well as to transport equipment.

\subsubsection{Wet Bulk Density}

The capacity of transport equipment, $W_{b}$, is expressed in terms of mass to be transported. Mass of a bulk material in a container can be calculated from the volume of the container and the average bulk density of the material,

$W_{b}=k \rho_{b} V$

where $\quad W_{b}=$ transporter capacity in wet mass (ton)

$\rho_{b}=$ wet bulk density of the biomass (ton $/ \mathrm{ft}^{3}$ )

$V=$ volume capacity of the transporter $\left(\mathrm{ft}^{3}\right)$

$k \quad=$ ratio of volume of the load over the full volume capacity of the container.

The coefficient $k<1.0$ represents less than full load situations and deviations from a straight plane for the top of the load in the transporter. It should be noted that $W_{b}$ has a maximum value based on legal weight limits. IBSAL checks the mass of the load in the transporter and if the load exceeds a maximum value, the mass in the container is set equal to the maximum wet mass. In this case IBSAL increases the number of transport loads to compensate for the lower mass in the container.

In the absence of data on bulk density of biomass at given moisture contents, IBSAL estimates the wet bulk density from the following mixtures formula (Peleg 1983):

$\frac{1}{\rho_{b}}=\frac{1-M_{w}}{\rho_{d}}+\frac{M_{w}}{\rho_{w}}$

where $\rho_{b} \quad=$ wet bulk density $\left(\mathrm{lb} / \mathrm{ft}^{3}\right)$

$\rho_{d}=$ dry bulk density $\left(\mathrm{lb} / \mathrm{ft}^{3}\right)$

$\rho_{w}=$ bulk density of water $\left(62.4 \mathrm{lb} / \mathrm{ft}^{3}\right)$

$M_{w}=$ wet basis moisture content (decimal fraction).

The dry bulk density, $\rho_{d}$, is a function of particle shape, size, and orientation in the container. Lam et al. (2007) gives an estimate of dry density of straw for uniform particle lengths. 
$\rho_{d}=a x^{-b}$

where $\rho_{d}=$ dry bulk density $\left(\mathrm{kg} \mathrm{m}^{-3}\right)$

$x=$ nominal particle size (length $\mathrm{mm}$ ).

Table 4 lists an estimates of values $a$ and $b$ for wheat straw, switchgrass, and corn stover. The values for stover were estimated using limited data presented in Sinners and Binversie (2004).

Table 4. Value of parameters $a$ and $b$ in equation 15

\begin{tabular}{llll}
\hline Biomass & a & b & Source of data \\
\hline Wheat straw & 142 & -0.410 & Lam et al. (2007) \\
Switchgrass & 435 & -0.540 & Lam et al. (2007) \\
Corn stover & 115 & -0.185 & Shinners and Binversie (2004) \\
\hline
\end{tabular}

\subsection{MOISTURE CONTENT OF BIOMASS BEFORE COLLECTION}

In section 2.3 we developed a method of estimating the moisture content of grain and biomass at the time grain is harvested and biomass is ready to be cut and shredded. For corn grain harvest, the combine harvest mechanism pinches stalks just below the ear. Much of the stalk remains anchored to the ground and is not easily removable. To collect biomass, a flail shredder or a forage harvester with cutter knife is used to cut and shred the above-ground stover (Sokhansanj et al. 2002). For wheat grain, combines generally cut straw 4 to 6 inches above the ground. The straw residue is then shredded and spread out from behind the combine. For biomass collection, the straw spreader is disengaged so the straw is left behind the combine in a windrow. Unlike stover, no shredding is required for wheat straw. For forages, including switchgrass, grass is mowed and left in a windrow. Windrows are raked into swaths for drying and for efficient collection (e.g. baling or loafing). This section develops equations that predict moisture content of the stalks laid in the field and waiting to be processed.

Section 2.3 described a method of estimating the moisture content of biomass stalks from the moisture content of grain at the time of grain harvest (equations 3 and 4). Biomass left in the field after grain harvest is subject to weather elements resulting in changes in its moisture content. The infield drying rate of crop residue and grasses has not been studied extensively. Sporadic data or anecdotal information indicates that broken stalks lose moisture easier than the standing crop. Shinners et al. (2003) observed that shredded stalks absorb moisture faster than standing crops due to rain and soil moisture. Womac et al. (2005) measured moisture content of shredded and nonshredded stover in an experimental field in Tennessee and confirmed this observation. Womac et al. (2005) fitted several forms of multiple regression equations to the data with the $\mathrm{R}^{2}$ ranging from 0.55 to 0.88 . The high $\mathrm{R}^{2}$ was for regression equations in which the number of days after sowing was included. Their prediction equation had a better fit to late maturing corn varieties than to the early maturing corn varieties.

\subsubsection{Transient Moisture Sorption Processes}

Although Womac et al. (2005) presented useful experimental data; the empirical moisture model can not represent time dependent moisture sorption processes. The model does not calculate moisture 
reduction during dry conditions or moisture uptake during wet conditions (rainy and/or high humidity). Nilsson (1999) reviewed literature on field drying of straw and concluded that instantaneous moisture content of straw can be assumed to be the sum of instantaneous external moisture content and instantaneous internal moisture content. In the following development we use a variation of Nilsson's approach.

$$
M=M_{i}+M_{x}
$$

where $\quad M=$ overall moisture content (mass fraction, dry basis)

$M_{i}=$ internal moisture content (mass fraction, dry basis)

$M_{x}=$ external moisture content (mass fraction, dry basis).

The time dependency of the internal moisture content is represented by the following first order thin layer drying equation,

$$
\begin{aligned}
& \frac{d M_{i}}{d t}=-a E_{p}\left(M_{i}-M_{e}\right) \\
& \text { where } \quad \begin{array}{ll}
a \quad=\text { a drying rate multiplier }\left(\mathrm{mm}^{-1}\right) \\
E_{p} & =\text { evaporation rate }(\mathrm{mm} / \mathrm{d}) \\
M_{e} & =\text { equilibrium moisture content (decimal fraction dry basis). }
\end{array}
\end{aligned}
$$

Nilsson (1999) estimated $a=1.2 \mathrm{~mm}^{-1}$ using in-field drying data for straw during daytime hours with no recorded precipitation $\left(M_{x}=0.0\right)$.

For the external moisture $M_{x}$, Nilsson (1999) wrote an instantaneous mass balance equating the rate of moisture change in the outer layer of biomass to the difference between precipitation and evaporation rates,

$$
\begin{aligned}
& \frac{d M_{x}}{d t}=b P-c E_{p} \\
& \text { where } \quad \begin{aligned}
P \quad & =\text { precipitation rate }(\mathrm{mm} / \mathrm{d}) \\
E_{p} & =\text { pan evaporation rate }(\mathrm{mm} / \mathrm{d}) \\
b, c & =\text { constants }\left(\mathrm{mm}^{-1}\right) .
\end{aligned}
\end{aligned}
$$

Nilsson (1999) wrote equation 18 with $\mathrm{M}_{\mathrm{x}}$ expressed in wet basis. Nilsson estimated coefficients $b$ and $c$ by a regression method using experimental moisture changes in a 12-hour period during which precipitation occurred. The resulting estimations were $b=23 \mathrm{~mm}^{-1}$ and $c=18 \mathrm{~mm}^{-1}$. For the time being we use Nilsson's constants but these need to be determined for each specific biomass when equation 18 is formulated correctly on a dry basis.

\subsubsection{Equilibrium Moisture and Relative Humidity}

Nilsson (1999) used the Modified-Henderson equation to calculate the equilibrium moisture content $M_{e}$ for use in drying equations.

$$
M_{e}=\frac{1}{100}\left[\frac{\ln (1-r h)}{-k_{1}\left(T+k_{2}\right)}\right]^{k_{3}}
$$


where $r h \quad=$ relative humidity (decimal fraction)

$$
\begin{array}{ll}
T & =\text { ambient air temperature }\left({ }^{\circ} \mathrm{C}\right) \\
k_{1}, k_{2}, k_{3} & =\text { constants }
\end{array}
$$

Table 5 lists the values of $k_{1}, k_{2}$, and $k_{3}$ for three biomass sources: wheat straw, switchgrass, and corn stover stalks from three different sources.

Table 5. Value of parameters $k_{1}, k_{2}$, and $k_{3}$ in equation 19

\begin{tabular}{lcccl}
\hline Biomass & $\boldsymbol{k}_{\boldsymbol{1}}$ & $\boldsymbol{k}_{\mathbf{2}}$ & $\boldsymbol{k}_{3}$ & \multicolumn{1}{c}{ Source } \\
\hline Wheat straw & $2.8 \times 10^{-4}$ & $2.80 \times 10^{2}$ & 1.03 & Nilsson (1999) \\
Switchgrass & $0.37 \times 10^{-4}$ & $374.00 \times 10^{2}$ & 1.76 & Colley et al. (2006) \\
Corn stover (stalks) & $8.5 \times 10^{-4}$ & $0.65 \times 10^{2}$ & 0.95 & Igathinathane et al. (2005) \\
\hline
\end{tabular}

${ }^{\mathrm{a}}$ The data are for switchgrass pellets

\subsubsection{Moisture Evaporation}

Pan evaporation, $E_{p}$, is the rate of water evaporation from a free surface. The following empirical equation given by Holman (1990) estimates pan evaporation rate,

$$
E_{p}=(0.37+0.0041 u)\left(P_{s}-P_{v}\right)^{0.88}
$$

where $\quad E_{p}=$ evaporation rate (inch/day)

$u \quad=$ mean wind velocity (mile/day)

$P_{s} \quad=$ saturation vapor pressure (inch $\mathrm{Hg}$ )

$P_{v} \quad=$ vapor pressure (inch $\mathrm{Hg}$ )

IBSAL uses the simplified Teten equation to estimate $P_{s}$ that is needed to calculate $P_{v}$,

$$
P_{S}=0.6108 \exp \left[\frac{17.27 T}{T+273}\right]
$$

where $P_{s}=$ saturation vapor pressure $(\mathrm{kPa})$

$$
T \quad=\text { dry bulb temperature }\left({ }^{\circ} \mathrm{C}\right)
$$

and

$P_{v}=P_{s}(r h)$

where $\quad P_{v}=$ vapor pressure $(\mathrm{kPa})$

$r h$ = relative humidity (decimal fraction)

Converting to SI units, equation 20 becomes:

$E_{p}=(3.21+0.078 u)\left(P_{s}-P_{v}\right)^{0.88}$

where $\quad E_{p}=$ evaporation rate $(\mathrm{mm} / \mathrm{d})$

$u=$ air velocity $(\mathrm{km} / \mathrm{d})$

$P_{s}=$ saturation vapor pressure $(\mathrm{kPa})$ 


$$
P_{v}=\text { vapor pressure }(\mathrm{kPa})
$$

IBSAL calculated vapor pressures (equations 21 and 22) and daily evaporation $E_{p}$ (equation 20 or 23) using daily temperature $T$, relative humidity $r h$, wind speed $u$. These weather data are extracted from the TMY2 data files. The daily data $(T, r h$, snowfall, rainfall, and the resulting calculations for evaporation $E_{p}$ ) are recorded in an Excel input data file. Appendix $\mathrm{C}$ describes step by step creation of the data input from TMY2.

\subsubsection{Numerical Solution to Transient Moisture Sorption Equations}

To establish initial conditions for internal and external moisture contents, $M_{i}$ and $M_{x}$, that are necessary for solving differential equations 17 and 18, Nilsson assumed that of the initial moisture content $20 \%$ can be considered external moisture content and $80 \%$ internal moisture content,

$M_{i, 0, w}=0.80 M_{0, w}$ and $M_{x, 0, w}=0.20 M_{0, w}$

Where $\quad M_{0, w} \quad=$ average moisture content of straw at $\mathrm{t}=0$ (decimal fraction wet basis)

$M_{i, 0, w} \quad=$ initial internal moisture content (decimal fraction wet basis)

$M_{x, 0, w} \quad=$ initial external moisture content (decimal fraction wet basis)

An explicit finite difference method (Euler's method) was used to solve equations 16 and 17,

$$
\begin{aligned}
& M_{i}(\Delta t+t)=M_{i}(t)+\left\{-a E_{p}\left(M_{i}(t)-M_{e}\right)\right\} t \\
& M_{x}(\Delta t+t)=M_{x}(t)+\left(b P-c E_{p}\right) d t \\
& M(\Delta t+t)=M_{i}(\Delta t+t)+M_{x}(\Delta t+t)
\end{aligned}
$$

Equations 25-27 are solved iteratively over a 24 hour period with $\Delta t=1$ hour. Input daily data on $T$, $r h, P$, and $E_{p}$ are read from the Excel input data file.

\subsection{MODELING DRY MASS LOSSES}

Biomass loses mass during various phases of harvest and during storage. For a crop residue such as stover, these losses may start from the time when the leaves start drying out. In general, we can divide dry mass losses into two categories: (1) those losses that happen during machine operations, and (2) those losses that result from biomass during a wait for the next operation. Biomass losses during a machine operation are mainly physical, i.e. losses due to physical disintegration of the biomass to a degree that it can not be collected from the field. Machine induced losses depend upon moisture content of the biomass at the time of harvest, yield, physical features of the field, design features of the machine, and the weather conditions (wind, rain, snow). Losses during a wait can be physical and/or chemical. Chemical losses are due to breakdown of structural and nonstructural carbohydrates. These breakdowns can be biotic such as mold and respiration. Abiotic breakdowns are oxidative reactions including a degree of pyrolysis.

Shinners and Binversie (2004) conducted tests on storing stover indoors and outdoors in Wisconsin. They used a variety of outside storage configurations including on the ground and on pallets. Table 6 is an extract of their data showing the range of moisture contents and storage configurations. Indoor storage had the least dry matter loss ranging from 2.2 to $4.9 \%$ for moisture contents ranging from 3.6 to $19.2 \%$. Bales stored outside picked up substantial moisture, especially those laid directly on the ground. The dry matter loss in these outside stored bales was also high, reaching up to $38.5 \%$ in the case of twine-wrapped bales. 
Table 6. Moisture content ranges and dry matter losses in stored stover over a period of 9 months

\begin{tabular}{lcc}
\hline \multicolumn{1}{c}{ Storage style } & Moisture content $(\% \mathbf{w b})$ & Dry matter loss $(\%)$ \\
\hline Square bales indoor & $13.2-19.3$ & $1.1-4.8$ \\
Round bales indoor & $13.6-19.2$ & $2.2-4.9$ \\
Round bales outside net wrap on pallets & $23.5-47.9$ & $7.0-8.2$ \\
Round bales outside twine on pallets & $30.9-55.4$ & $11.0-36.1$ \\
Round bales outside net wrap on ground & $30.3-53.3$ & $10.7-14.7$ \\
Round bales outside twine on ground & $36.4-59.1$ & $14.3-38.5$ \\
\hline
\end{tabular}

Source: Shinners and Binversie (2004)

Figure 6 depicts the flow of biomass while it is in a queue waiting to be processed in a machine (workstation). While in queue, the biomass is subject to the elements (temperature, precipitation). $C_{I}$ is the fraction of the dry matter biomass lost while in the queue. Of the original $Y_{1}$ (dt/ac) of biomass, $Y_{2}(\mathrm{dt} / \mathrm{ac})$ is available to the machine,

$Y_{2}=Y_{1}\left(1-C_{1}\right)$

Similarly, a fraction of the biomass is lost during a machine operation. The net amount of biomass exiting the machine is $Y_{3}(\mathrm{dt} / \mathrm{ac})$,

$Y_{3}=Y_{2}\left(1-C_{2}\right)$

or $\quad Y_{3}=Y_{1}\left(1-C_{1}\right)\left(1-C_{2}\right)=Y_{1}\left[1-\left(C_{1}+C_{2}\right)+C_{1} C_{2}\right]$

Equation 30 reveals that dry matter losses can not be added and should be calculated individually for each operation. Buckmaster (1990) calls the loss of biomass while in queue invisible loss and biomass loss as a result of machine operation visible loss.

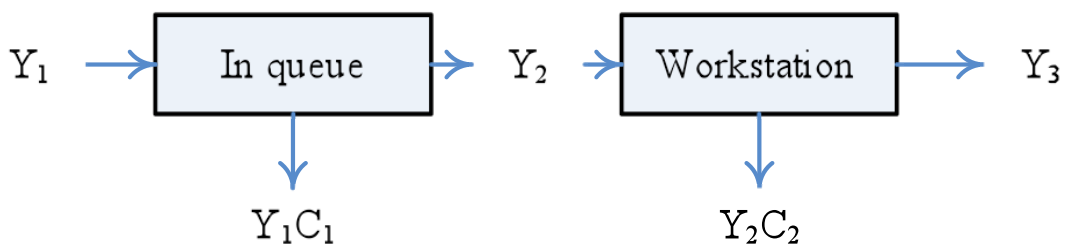

Figure 6. Dry matter loss in the field while in a queue followed by dry matter loss at a workstation (machine operation)

\subsubsection{Modeling Dry Matter Loss in Queue}

Biomass stays in queues at several points along the supply chain. Once the grain is harvested biomass stays in the field either standing (in case of corn) or lays in the field in the case of wheat in order to be shredded and or picked up. While in the field waiting for the machine, the biomass is exposed to 
weather. Dry matter losses in the field (invisible losses) are mostly the result of chemical breakdown of the plant structure and composition. These may happen due to respiration of the plant cells and other biochemical reactions. Respiration is in essence the breakdown of carbohydrates (simple and complex sugars) in the presence of carbon dioxide and heat energy.

Bales may also remain on the field for a period of time until they are transported to a more permanent storage area. Storage is either located next to the farm or at a larger central storage site. Protected or unprotected, biomass bales are exposed to elements and will undergo a degree of chemical degradation. Chopped and ensiled material also undergoes chemical changes that result in loss of dry matter.

Chemical breakdowns are time dependent and are more difficult to model than physical breakdowns. Time varying moisture content and temperature make the calculation and aggregation of dry matter losses more difficult than those losses attributed to machine operation. The available published data for dry matter losses are given after a long period of storage (6 to 12 months).

Dry matter loss due to chemical decomposition of plant material occurs both in the field while the biomass is loose and also when it is packaged in the form of bales. Igathinathane et al. (2008) have investigated and modeled the number of days before visible mold appears on corn stalks stored at a given temperature and water activity,

$$
d_{i}=\exp \left(7.10-0.04 T_{i}-3.52 a_{w i}\right)
$$

where $\quad d_{i}=$ the number of days before mold appears (d)

$T_{i}=$ constant temperature $\left({ }^{\circ} \mathrm{C}\right)$,

$a_{w i}=$ water activity (decimal fraction)

Bern et al. (2002) associated dry mater loss to visible mold. According to Steele et al. (1969), a dry matter loss of $0.5 \%$ was associated with $5 \%$ of the mass of corn grain being infested with visible mold. Such a relation for stover is not available. IBSAL assumes 5\% dry matter as a baseline to calculate the loss of quality of biomass. Using an analogy to corn grain, a 5\% dry matter loss is equivalent to infestation of $50 \%$ of the biomass with mold. Sokhansanj et al. (2003) developed a similar equation to (31) to estimate the number of days before they observed visual molds on alfalfa cubes,

$\ln \left(d_{i}\right)=a+b T_{i}+c M C_{i}$

where $\quad M C_{i} \quad=$ moisture content of the cubes (decimal wet basis)

$d_{i} \quad=$ the number of days before mold appears $(\mathrm{d})$

$T_{i} \quad=$ constant temperature $\left({ }^{\circ} \mathrm{C}\right)$

Sokhansanj et al. (2003) did not relate the moldiness of cubes to dry matter loss. They considered the presence of mold as the sign of complete spoilage of a load of cubes. Equation 32 was used to predict the length of time cubes could be safely stored. Obviously the issue is more complex than these assumptions and the topic requires further research.

Blunck et al. (2003) reported on storage of rice straw bales in California. They tested storage outside without cover, with cover, storage inside a building, and under a shed. Their published data included initial and quarterly moisture contents along with acid insoluble ash data. They calculated a dry matter loss from acid insoluble ash. For IBSAL, Blunck et al.'s data was used to estimate the number of days to reach $5 \%$ dry matter loss. Equation 32 without the temperature term, 
was fit to the number of days and the corresponding average moisture contents. Table 7 lists the estimated $a$ and $b$ values. Note the estimated parameters do not include a temperature coefficient due to the lack of data. In addition to dry mass loss, Shinners and Binversie (2004) also provided initial and final moisture content of stored stover bales. These data were interpolated to calculate number of days to reach a 5\% dry mass loss. Constants $a$ and $b$ were estimated. These are listed in Table 7 along with the $\mathrm{R}^{2}$ values.

Upon inspecting the pooled data from baled rice straw and baled corn stover storage, it was noted that dry mass loss, though from two different geographical areas (California for straw and Wisconsin for stover), could be pooled to develop a single equation to predict dry matter loss. Table 7 lists the estimated values of $a$ and $b$ along with the corresponding $\mathrm{R}^{2}=0.72$. The current version of IBSAL contains equation 33 with the pooled coefficients $(a=7.072, b=-0.083)$.

Table 7. Estimated constants $a$ and $b$ in equation 33

\begin{tabular}{lccc}
\hline \multicolumn{1}{c}{ Biomass } & $\boldsymbol{a}$ & $\boldsymbol{b}$ & $\mathbf{R}^{\mathbf{2}}$ \\
\hline Rice straw & 6.603 & -0.068 & 0.82 \\
Corn stover & 8.989 & -0.144 & 0.80 \\
Pooled data (straw and stover) & 7.072 & -0.083 & 0.72 \\
\hline
\end{tabular}

\subsubsection{Integrating Dry Matter Loss}

Equation 33 predicts number of days to reach 5\% dry matter loss when biomass is at constant moisture content. In reality though, the moisture content of the biomass is not a constant and varies with time. Fraser and Muir (1981) developed an integration procedure to estimate the dry matter losses from varying moisture conditions for grain storage. IBSAL applies this method to estimate the fraction of dry mass loss,

$S_{i}=\frac{\Delta t}{d_{i}}$

where $S_{i} \quad=$ fraction of dry matter loss during time interval $\Delta t$

$\Delta t=$ time interval during which moisture is at a constant moisture is constant.

$d_{i}=$ number of days for the biomass to reach 5\% dry matter loss

The daily dry matter loss while biomass is waiting in a queue or in storage is,

$d m l_{i}=L_{f} W_{i} S_{i}$

where $\quad d m l_{i}=$ daily dry matter loss $(\mathrm{dt})$

$L_{f}=$ multiplier representing dry matter losses for the storage configuration

$W_{i}=$ mass of biomass $(\mathrm{dt})$

$S_{i} \quad=$ fraction of dry matter loss during time interval $\Delta T$

From the reported experiments on storage of biomass, it is evident that most of the spoilage happens on the perimeter of bales or perimeter of the stack. The spoiled bales are those that are mostly 
exposed to weather elements. Bales that are not exposed to weather conditions (e.g. stored in a building) experience the least dry matter loss.

The values of $L_{f}$ vary with the degree of biomass exposure to the elements. The data in Table 6 showed that variations in dry mass loss may range from $1.1 \%$ for square bales stored inside a building to almost $39 \%$ for bales stored outside. As was mentioned earlier, several reports indicate that bales in the periphery of a stack show the most sign of spoilage. There is a high variability in the relationship between moisture content of biomass and number of days to reach the 5\% dry matter loss level. Based on the general knowledge available about biomass storage, the first author suggests several values to be used for $L_{f}$ to adjust the calculated $d_{i}$. These suggested $a d$-hoc values along with a commentary are listed in Table 8. Further research is needed to either develop more robust equations or improve upon values for the coefficient $L_{f}$.

Biomass dry matter loss reaches $5 \%$ when the value of $S$ becomes one,

$$
S=\sum_{i=1} \frac{\Delta t}{d_{i}}=1
$$

For switchgrass, Shinners et al. (2006) tested the productivity of baling and bale storage for round bales of switchgrass in Wisconsin. Dry bales stored outdoors for 9 and 11 months averaged 3.4, 7.7, 8.3 , and $14.9 \%$ dry matter loss for bales wrapped with plastic film, net wrap, plastic twine, and sisal twine respectively. Bales stored indoors averaged 3.0\% dry matter loss. Preservation by ensiling bales in a tube of plastic film produced average dry matter losses of $1.1 \%$.

Table 8. Suggested ${ }^{\mathrm{a}}$ multiplier factors for use in predicting dry matter loss while biomass is in a queue

\begin{tabular}{lrll}
\hline \multicolumn{1}{c}{ Condition or format of biomass } & $\boldsymbol{L}_{f}$ & \multicolumn{1}{c}{ Remarks } \\
\hline Portions of stalk is still standing & 0.40 & After grain is combined and biomass is left on the field \\
Loosely spread in the field & 0.45 & After shredding (hog) operation \\
Biomass is in windrow & 0.35 & After raking \\
Twined bales scattered in the field & 0.30 & Bales are on stubble \\
Net wrapped bales scattered in the field & 0.25 & Bales are on stubble \\
Bales stacked uncovered & 0.20 & Ground is prepared (no moisture ingress) \\
Bales in plastic tubes & 0.15 & Bales continuously wrapped in plastic \\
Bales stacked covered (tarped) & 0.10 & Stacks are covered with tarp \\
Baled biomass stored in a building & 0.05 & Shed or enclosed building \\
\hline
\end{tabular}

${ }^{a}$ The recommended values are input variables and can be changed. The senior author of this document suggests these values as inputs.

\subsubsection{Dry Matter Loss in a Workstation}

In IBSAL, a workstation is a machine that operates on biomass. Dry matter losses as a result of machine operations are not time dependent. The losses are mostly a function of biomass moisture content and yield (crop density). Machine design and operating conditions such as travel speed and 
roughness of the field also affect dry matter loss (Pitt, 1990). Buckmaster (1990) showed that the dry mass loss for hay crops is a function of crop yield and crop moisture content. Figure 7 depicts Buckmaster's data showing the dry matter loss in a rake operating on a forage crop. At $2 \mathrm{dt} / \mathrm{ac}$, the dry matter loss at 30\% moisture content (wb) was 25\%. Dry mater loss decreased to $5 \%$ for the same moisture content but for an increased yield from 2 to $4 \mathrm{dt} / \mathrm{ac}$. It appears for a leafy hay crop such as alfalfa, an increased yield reduces the potential for loss of dry matter due to leaf shattering.

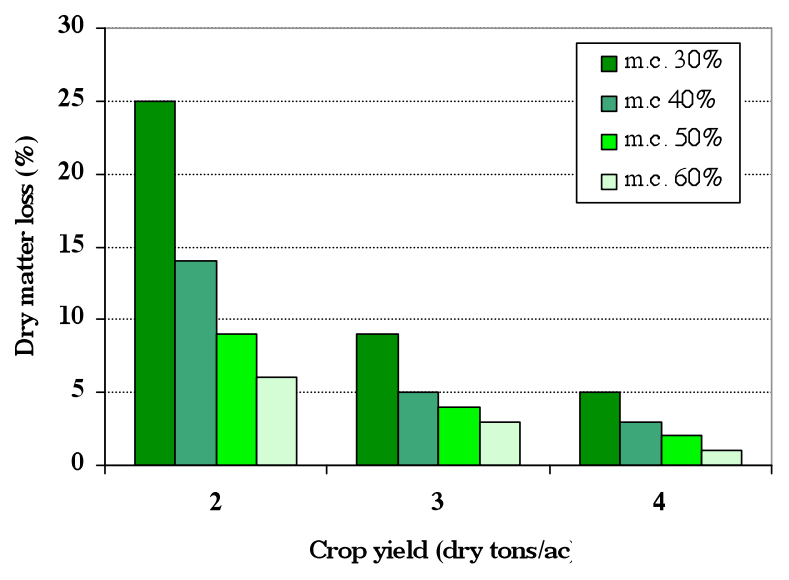

Figure 7. Dry matter loss for a rake operating on a crop at various moisture contents and dry matter yields (Source: Buckmaster 1990)

These losses are difficult to estimate for biomass unless reliable data for a particular machine's performance are available. In one study, Pordesimo et al. (2004) found that roughly $3 / 4$ of the leaf fraction of stover was lost when the standing corn stalk dried in the field for one month. These leaves were lost in a subsequent shredding and windrowing of the biomass.Richey et al. (1982) reported the most detailed account of mass balance for corn stover in the field. Though their account of dry matter loss is now more than 25 years old, their procedure for estimating net collectible biomass is instructive. Tests by Richey et al. were conducted on a corn farm in Indiana. They measured a corn grain yield of 3.9 tons/ac (moisture content was not specified and we may assume it is a dry mass). Based on the grain yield and using the 1:1 rule for grain:stover, we estimated $3.9 \mathrm{dt} / \mathrm{ac}$ of stover yield (Table 9). They used a 14-ft wide flail pickup to shred, lift, and gather the material in a windrow. The cut height was set at 3" above the ground to minimize collection of soil with the shredded material. Approximately 2.1 ton/ac of stover was collected in the windrow. The stover left on the field amounted to 1.0 ton/ac for a total of 3.1 ton/ac. They could not account for the remaining 0.8 ton/ac. They estimated $50 \%$ of the uncollected material was trampled stalks lying on damp ground. These stalks were pressed into the ground by the machinery used for the grain harvest. Table 9 shows that the final collected material was $25 \%$ of the original above ground biomass.

Table 10 is extracted from Prewitt et al. (2007) showing the collection efficiency of several harvest methods for stover. The collection efficiencies varied from a low 32\% using a mower and rake to a high of $94 \%$ using a flail type mower with windrowing capability. Unfortunately in none of these experiments the collection efficiency of the baling process was parsed out. Nevertheless, data in Table 10 may indicate that increasing operations in the field to remove more stover could be counter productive. An estimate of 50\% overall removal rate looks reasonable based on the works of Shinners et al. (2003) and Shinners and Binversie (2004). 
Table 9. Summary of mass balances in a corn stover harvesting experiment

\begin{tabular}{lcc}
\hline \multicolumn{1}{c}{ Operations } & $\begin{array}{c}\text { Net yield } \\
(\mathbf{d t} / \mathbf{a c})\end{array}$ & $\begin{array}{c}\text { Recovered biomass } \\
(\mathbf{\%})\end{array}$ \\
\hline Assumed total yield & 3.87 & 100 \\
Windrowed & 2.07 & 53 \\
Not windrowed & 1.01 & 49 \\
Baled, or stacked & 0.97 & 96 \\
Overall collection efficiency & & 25 \\
\hline
\end{tabular}

Source: Richey et al. (1982)

Table 10. Stover collection efficiencies for several harvest equipment

\begin{tabular}{lccc}
\hline \multicolumn{1}{c}{ Stover collection scenario } & $\begin{array}{c}\text { Baled } \\
\text { stover } \\
\text { (dt/ac) }\end{array}$ & $\begin{array}{c}\text { Estimated } \\
\text { stover } \\
\text { available } \\
\text { (dt/ac) }\end{array}$ & $\begin{array}{c}\text { Collection } \\
\text { efficiency } \\
(\%)\end{array}$ \\
\hline Bale only (combine straw chopper on ) & 1.34 & 2.96 & 45 \\
Rake uncut stover into a windrow and bale & 1.25 & 2.54 & 32 \\
Rotary mower, rake into a windrow, and bale & 0.85 & 2.63 & 94 \\
Flail type mower with windrow forming shield and bale & 1.97 & 2.10 & 74 \\
Bale behind combine with straw chopper disengaged & 2.02 & 2.72 & \\
\hline
\end{tabular}

Source Prewitt et al. (2007)

In the present version of IBSAL, the percent of losses for each machine (workstation) is a user defined input. The input is part of specifications for each piece of equipment. Table 11 lists estimates for machine losses based on the first author's experience with hay and forage crops. Most of the losses during machine operation are due to breakage and fragmentation of biomass into small pieces. These are lost in wind or mixed with soil. In future work, equations will be developed to estimate biomass loss due to machine operation and for each piece of equipment will be of the form:

$d m l_{m}=f(m c, y, g)$

Where $\quad d m l_{m} \quad=$ dry matter loss due to machine operation

$m c \quad=$ moisture content,

$y=$ yield (crop density dt/ac),

$g \quad=$ ground conditions (e.g. roughness).

Other conditions such as wind, occasional showers, dew, and operator performance may influence the function $d m l_{m}$ in equation 37. 
Table 11. Estimates of dry matter losses during various field operations ${ }^{a}$

\begin{tabular}{lc}
\hline \multicolumn{1}{c}{ Operation } & $\begin{array}{c}\text { Maximum dry matter loss due } \\
\text { to machine operation or being } \\
\text { left in the field (\%) }\end{array}$ \\
\hline Lost from being left in the field as stubble & 10 \\
Lost during combining & 3 \\
Lost during mowing, shredding, raking & 5 \\
Lost during baling, loafing, chopping & 10 \\
Lost during stacking & 2 \\
\hline
\end{tabular}

${ }^{\mathrm{a}}$ Estimates based on first author's experience. Estimates do not include dry matter losses while biomass is in queue.

\subsubsection{Net Yield}

The tonnage remaining after dry matter losses during machine operation and in the queue is passed on to the next operation. For each operation, a net yield is calculated by dividing the biomass tonnage by the area of the field. Conservation allowance (Gallagher et al. 2003) represents an amount of biomass that must be left on the field for soil conservation. As a general rule, the Natural Resource Conservation Service (NRCS) requires that $30 \%$ of the field must be covered in the spring. Gallagher et al. (2003) estimate that $0.715 \mathrm{dt} / \mathrm{ac}$ fulfills that requirement,

$Y_{\text {cons }}=0.715$

where $Y_{\text {cons }}=$ yield to meet $30 \%$ conservation allowance $(\mathrm{dt} / \mathrm{ac})$.

Gallagher et al. (2003) estimate $Y_{\text {cons }}$ to be $0.375 \mathrm{dt} / \mathrm{ac}$ for wheat and other small grains. However these minimum recommendations should be increased if conditions for erosion (water and wind) are present (Andrews, 2006). IBSAL checks the net yield after the last field operation (for example baling) against the conservation allowance,

If $\left[\left(Y_{I^{-}} Y_{\text {bale }}\right)<Y_{\text {cons }}\right]$ then $Y_{\text {bale }}=Y_{1}-Y_{\text {cons }}$

where $Y_{\text {bale }} \quad=$ net yield calculated after baling operation $(\mathrm{dt} / \mathrm{ac})$

$Y_{l} \quad=$ initial yield calculated from biomass to grain ration $(\mathrm{dt} / \mathrm{ac})$

$Y_{\text {cons }}=$ yield $(\mathrm{dt} / \mathrm{ac})$ to meet $30 \%$ conservation allowance.

$Y_{\text {bale }}$ is replaced with the net yield calculated after operations that replace baling (e.g. loafing, field chopping).

\subsection{ENERGY INPUT AND EMISSIONS}

Energy input to a machine is the application of power to perform a function over time. ASAE EP496.3 (ASAE 2006b) outlines a detailed procedure for calculating the power input to field equipment. The procedure requires specific data on soil texture and mass of equipment (with load) to calculate rolling resistance and from there pull or push forces. Other power input components are mechanical (rotational), hydraulic, and electric power inputs. ASAE EP496.3 also recommends that the average annual fuel consumption for a specific make and model of tractor can be estimated from the Nebraska Tractor Test data. The estimated formula is, 
where $F=$ average gasoline used for equipment $(\mathrm{gal} / \mathrm{hr})$

$P_{\text {pto }}=$ rated pto power $(\mathrm{hp})$.

ASAE EP 496.3 specifies a diesel tractor will use approximately $73 \%$ as much fuel in volume as a gasoline tractor. ASAE EP 496.3 also specifies that fuel consumption for engines not included in Nebraska Tractor Test Data may be estimated by equation 40 by the advertised PTO power or by comparing them to a tractor engine with similar displacement.

The current version of IBSAL calculates the energy used to power equipment from the manufacturer's rated power (hp or $\mathrm{kW}$ ) specified for that equipment. The specified (rated) power would obviously be larger than the real power to ensure the equipment perform satisfactory in most conditions.

The higher heating value of diesel fuel is $138,890 \mathrm{Btu} / \mathrm{gal}$. West and Marland (2002) list carbon emissions from diesel-fuelled equipment at a rate of $21.95 \mathrm{~kg} \mathrm{C} / \mathrm{GJ}$ (higher heating value basis), which, converted to English units, is $7.08 \mathrm{lb} \mathrm{C/gal}$. Actual fuel consumption for a particular operation may vary from the average fuel consumption which equation 40 estimates.

\subsection{COST RATES}

The cost of machinery and buildings is expressed as a sum of fixed and variable costs. The following elements constitute the costs of building and machinery,

- Capital recovery (depreciation and interest)

- Repairs and maintenance

- Fuel and lubrication

- Insurance, housing, and taxes

- Labor.

The authors have published the procedure outlined here for calculating elements of the machinery costs (Sokhansanj and Turhollow 2002, Sokhansanj and Turhollow 2004, Turhollow and Sokhansanj 2007).

\subsubsection{Capital Recovery}

IBSAL uses the AAEA (2000) method for calculating the annualized value for capital,

$$
\begin{aligned}
& R=\left[P-\frac{S}{(1+i)^{n}}\right] \frac{i(1+i)^{n}}{(1+i)^{n}-1}+P k+\frac{S i}{(1+i)^{n}} \\
& \text { where } R \quad=\text { annual fixed cost }(\$) \\
& P \quad=\text { purchase price of equipment }(\$) \\
& i=\text { annual interest rate (fraction decimal) } \\
& k=\text { sum of rates for taxes, housing (shelter), insurance (fraction decimal) } \\
& S \quad \text { = salvage value }(\$)
\end{aligned}
$$

The salvage value, $S$, is a fraction of the initial purchase price. List price of machinery is different from purchase price, $P$. The AAEA (2000) specifies that the difference between purchase price and 
list price is $15 \%$. In an example, the AAEA assumes that the list price is $10 \%$ more than the purchase price (or purchase price is $90.9 \%$ of list price). In IBSAL purchase price is assumed to be $90 \%$ of the list price.

\subsubsection{Salvage Value}

Salvage value is computed to determine interest and depreciation. ASAE D497.5 (ASAE 2006a) refers to Cross and Perry $(1995,1996)$ as sources of data for calculating salvage values. The salvage value at the end of year $n$ (as a fraction of the list price) is expressed as follows,

$S=\left(C_{1}-C_{2} n^{0.5}-C_{3} h^{0.5}\right)$

where $S=$ salvage value $(\$)$

$n \quad=$ years

$h \quad=$ average yearly operation (hr).

Coefficients $C_{1}, C_{2}$, and $C_{3}$ are given in Table 12. Powered equipment has a coefficient $\left(C_{3}\right)$ for hours of annual use. The salvage values for windrowers and forage harvesters are calculated using coefficients for swathers and all other harvest equipment category. The salvage values for telescopic handlers, transport equipment, and other equipment than those specified are calculated using the coefficients for the miscellaneous equipment category.

The salvage value for buildings is difficult to estimate and a common method used is simply to estimate a long life and minimal salvage value (AAEA 2000). For a biomass collection operation this is not an issue. For preprocessing operations, this is important for accounting for buildings that house processing equipment and for storage. IBSAL assumes that buildings have a 20-year life with no salvage value and the preprocessing equipment has a 15-year life with a $10 \%$ (undiscounted) salvage value.

Table 12. Coefficients for the ASAE remaining value equations

\begin{tabular}{lccccc}
\hline \multicolumn{1}{c}{ Equipment type } & $C_{1}$ & $C_{2}$ & $C_{3}$ & $R F_{1}$ & $R F_{2}$ \\
\hline Tractors < 60 kW (80 hp) & 0.981 & 0.093 & 0.0058 & $a, b$ & 2.0 \\
Tractors 60-112 kW (80-150 hp) & 0.942 & 0.100 & 0.0008 & $a, b$ & 2.0 \\
Tractors > 112 kW (150 hp) & 0.976 & 0.119 & 0.0019 & $a, b$ & 2.0 \\
Mowers & 0.756 & 0.067 & - & 0.44 & 2.0 \\
Balers & 0.852 & 0.101 & - & 0.10 & 1.8 \\
Combines & 1.132 & 0.165 & 0.0079 & 0.12 & 2.3 \\
Swathers and all other harvest (forage) & 0.791 & 0.091 & - & 0.03 & 2.0 \\
equipment & 0.786 & 0.063 & 0.0033 & 0.06 & 2.0 \\
Skid-steer loaders and all other vehicles & 0.943 & 0.111 & - & 0.41 & 1.3 \\
Miscellaneous equipment & & & &
\end{tabular}

$a=0.007$ for 2 wheel drive tractor, $b=0.003$ for 4 -wheel drive tractor

Source: ASABE (2006a) 


\subsubsection{Repairs and Maintenance}

ASAE EP496.3 (ASABE 2006c) uses equation 43 for estimating repair and maintenance costs, $C_{r m}$ :

$C_{r m}=R F_{1} P\left(\frac{h}{1000}\right)^{R F_{2}}$

where $P \quad=$ list price of the machine

$h \quad=$ hours of accumulated use

Table 12 lists $R F_{1}$ and $R F_{2}$ from ASAE D497.5 (ASABE 2006b). When $h$ equals the hours of useful life, then accumulated repairs equal lifetime repairs; the equipment is used for its useful lifetime. Coefficients $R F_{1}$ and $R F_{2}$ spread repair costs over time, spreading more cost to later in a machine's life.

\subsubsection{Fuel and Lubrication}

ASAE D497.5 (ASABE 2006b) recommends using actual power used to pull implements to calculate fuel use. For specific make and model of a tractor, it is recommended to use the Nebraska Tractor Test Data. In the absence of specific data, average diesel consumption over the entire year is estimated by equation 40 . The amount of lubricating oil used can be estimated using equations from ASAE D497.5 (ASABE 2006b). However, this is not necessary. ASAE EP496.3 (ASABE 2006c) estimates that lubrication costs, including the oil and filter, are $15 \%$ of fuel costs.

\subsubsection{Insurance, Housing, and Taxes}

Insurance, housing, and taxes are a fixed costs of equipment. Housing is the cost of shelter for equipment and taxes are paid on buildings. AAEA (2000) refers to this as taxes, insurance, and shelter. If actual data are not available, the ASABE (2006c) suggests using the following multipliers: taxes 0.01 , housing 0.0075 , and insurance 0.0025 , for a total of 0.02 to be applied to the purchase price as the annual cost of insurance, housing, and taxes. AAEA (2000) and IBSAL use $2 \%$ of the average of purchase price, $P$, and salvage value, $S$.

$I H T=0.02\left(\frac{P+S}{2}\right)$

where $I H T=$ annualized insurance, housing, and taxes.

\subsubsection{Labor}

Farm labor rates can be obtained from, Farm Labor, a quarterly publication of the National Agricultural Statistics Service of the U.S. Department of Agriculture. They list a number of farm labor rates: field, livestock, field and livestock, and all hired workers for 18 regions of the United States. Based on the 2004 data for four regions of the Midwest (Lake, Corn Belt I, Corn Belt II, and Northern Plains), the average wage rate was $\$ 9.70 / \mathrm{hr}$. With an assumed fringe benefits rate of $30 \%$, the labor rate was $\$ 12.61 / \mathrm{hr}$. It is a common assumption in crop budgeting that more labor time is required than machine time in the field. AAEA (2000) assumes that 1.2 labor hours are required for each machine hour. IBSAL uses this assumption, so labor cost is $\$ 15.13 /$ machine hour. 


\section{IMPLEMENTATION}

Figure 8 shows the flow of biomass through an IBSAL collection network. In this generalized diagram, a discrete item is a specified land area that is ready for harvest. The number of fields ready for harvest is determined based on the harvest progress calculations previously described in section 2.2. Attributes of the discrete item (field) are moisture content, yield, minimum and maximum distances from the field to a stacking (or storage) location. As items enter the network on a daily basis, weather data for that particular day are also received from the database. Each item will accumulate costs when the item passes through a unit operation. For example, if an item is processed by a baler, the cost of the baler will be added to the costs that the item has so far accumulated from previous operations. An item remains in the field or in storage if the subsequent operation is busy. During this wait time, changes in moisture content and dry matter loss due to precipitation, drying, or degradation are estimated using equations described earlier.

Items (land units) are generated daily for 365 days (365 items). Daily moisture contents are calculated and assigned to items generated for that day. The number of items per day is calculated from weekly harvest progress data (USDA-NASS data). Interpolations are done to convert from weekly harvest progress to daily harvest progress (daily number of land units ready to be harvested). Items are queued in the buffer and released one item at a time.

IBSAL was developed using Extend V.6 (www.imaginethatinc.com), a commercially available dynamic modeling language, to implement the collection and transport operations. Extend can be

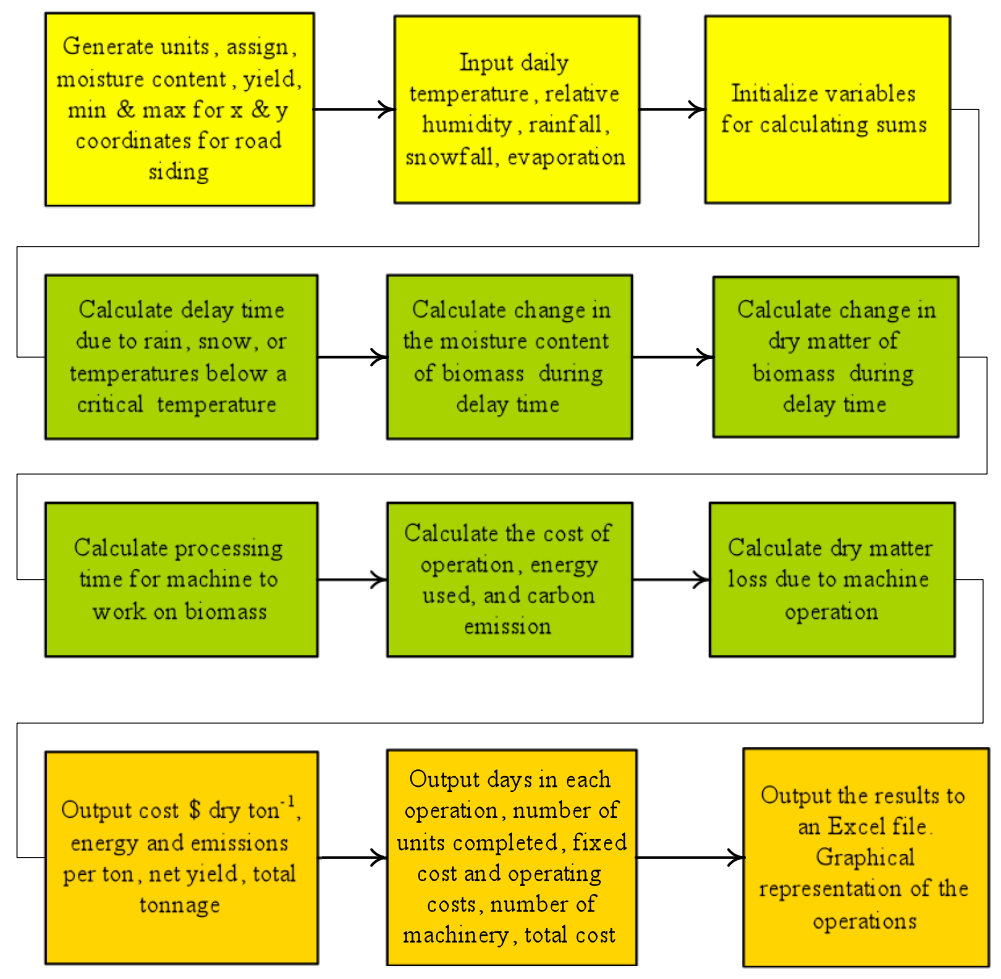

Figure 8. Flow diagram for discrete modeling of biomass collection operations. For transport, the model is similar except there are no weather delays 
used in two modes: ready to use graphical blocks and a $\mathrm{C}$ based computer language with many built in functions. The graphical blocks carry out specific tasks such as queues, decisions, computations, full scale programming and calculations, and input and output functions. The accessible $\mathrm{C}++$ like programming code, called ModL, is available to the user for programming and interfacing with graphical blocks. A model is created by dragging blocks from a library to a worksheet, connecting these boxes, and then entering appropriate data in the dialog boxes available for each block. The program is capable of modeling continuous and discrete processes (Krahl, 2001). IBSAL operates in a combined discrete and continuous mode.

In the discrete modeling approach, items and their attributes (e.g. yield, moisture content, cumulative cost, etc) are generated at specified times (daily in IBSAL). An item moves through a network of workstations. Workstations are unit operations or processes. Grain harvest, shredding of biomass, baling, and transporting are examples of unit operations. Drying or wetting and calculating dry matter losses are example of processes. If an operation (a workstation) is busy, the item remains in a queue until the station can accept the item. The item's attributes may change while being operated on or processed and new attributes may be assigned. Once the workstation completes its operation, the item exits that station. The item enters the next queue or next station. The movement of the item through operations and processes continues from one station to the next until it passes through all stations and exits the network. Before exiting, the current values of the item attributes are recorded on the output file (Excel).

In IBSAL development, each operation or process is written in the form of a module. Modules are placed in the Extend Library. To create a biomass feedstock supply chain simulation, selected modules are dragged from the IBSAL library and dropped into an Extend worksheet. The modules are arranged in a logical manner and chained together to create a network such as the one shown in Figure 9. An IBSAL user's manual that explains the details of how to create and run feedstock simulations along with organizing the input and output files will be published shortly. The target data for publication of the User's Manual is fall of 2008.

\section{EXAMPLES}

In this section, two examples of biomass feedstock supply simulation that are developed using the IBSAL model are described. The first example is for collecting corn stover using a baling system. The second example is transporting these bales from stacks to a biorefinery.

\subsection{COLLECTION}

The supply system demonstrated here is a scenario of collecting stover in Iowa. The collection sequence consists of shredding/windrowing stover and making large square bales (4'x4'x8'). An automated bale collector (Stinger) collects and moves 8 bales at a time to the edge of the field. A bale wrapper wraps a stack of two bales into a continuous tube. The wrapped bales are left at the side of the farm until these bales are transported to a plant. Figure 9 shows the image of IBSAL modules comprising the supply system. The details of equipment specifications and costs of equipment used in this example are listed in Appendix A.

Weather data input to the model were from typical meteorological year TMY2 data for Des Moines, IA (See Appendix B). The progress of harvest in Table 13 is for a five year average of the 2002-2006 
crop years. This data was downloaded from the USDA-NASS web site (http://www.nass.usda.gov/QuickStats/PullData_US.jsp). For this particular example it is noted that harvest started on week 36 (1\% harvested) and progressed to week 47 when the harvest was 99\% complete. Previously, Table 1 showed that for Iowa for crop year 2005 harvest started earlier (2\% harvested in week 36) and by week $45,94 \%$ of the land was harvested. This year to year variation in progress of harvest is not unexpected.

Table 13. Five year average (2002-2006) of progress of corn grain harvest in Iowa

\begin{tabular}{llllllllllllll}
\hline Week number & 35 & 36 & 37 & 38 & 39 & 40 & 41 & 42 & 43 & 44 & 45 & 46 & 47 \\
\hline$\%$ harvest progress & 0 & 1 & 3 & 6 & 10 & 16 & 29 & 49 & 68 & 83 & 92 & 97 & 99 \\
\hline
\end{tabular}

Source: http://www.nass.usda.gov/QuickStats/PullData_US.jsp

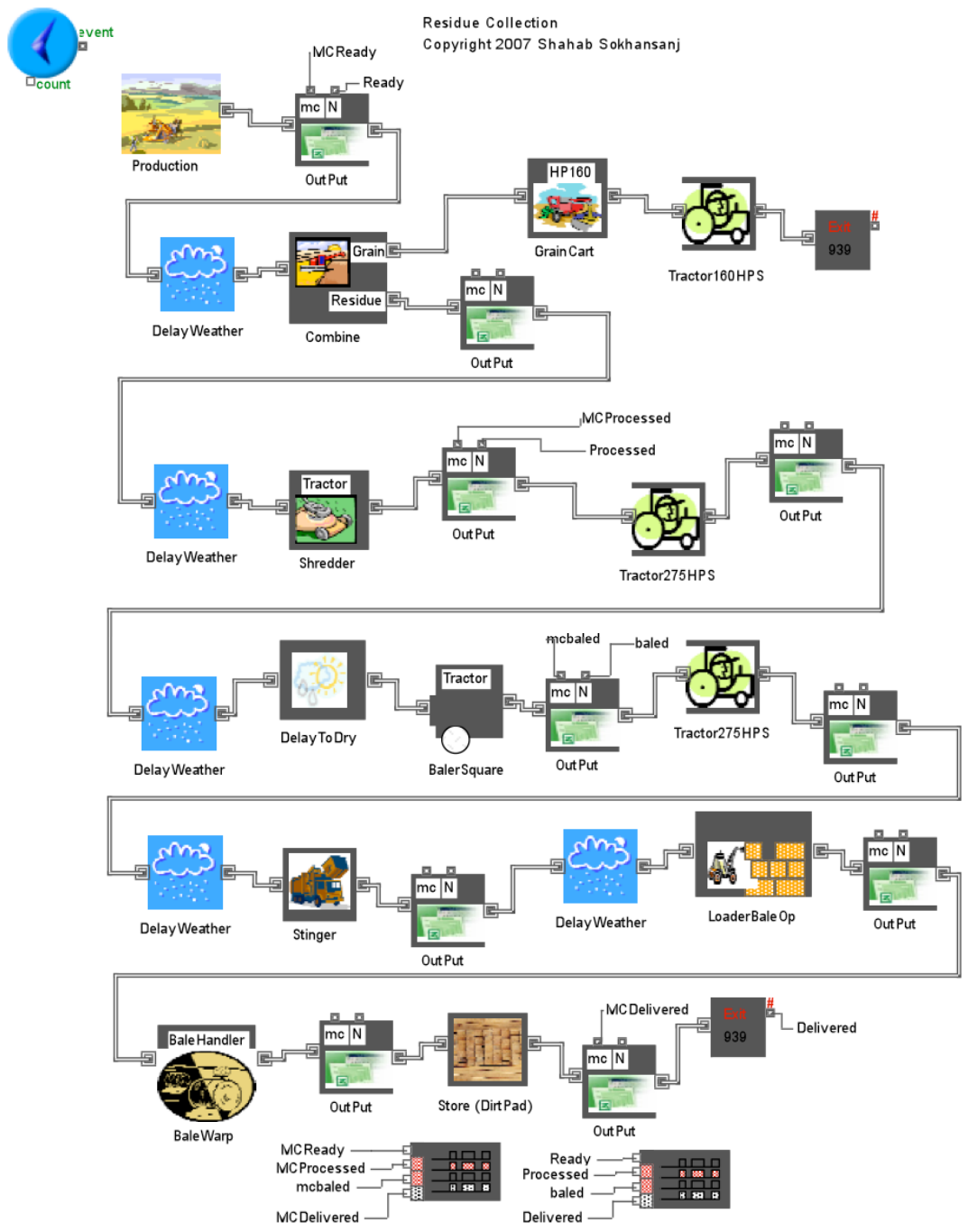

Figure 9. An image of IBSAL with operations for shredding, baling, stacking chained to form a stover harvest assembly 
Table 14 lists input data to the model. In this simulation IBSAL assumes that gross biomass available after grain harvest is 4.38 ton/ac. This gross yield is based on a grain yield of $185 \mathrm{bu} / \mathrm{ac}$ that equates a theoretical above ground biomass of $4.38 \mathrm{dt} / \mathrm{ac}(56 \mathrm{lb} / \mathrm{bu}$ at $15 \%$ moisture content and a biomass to grain ratio of 1:1). Other inputs are distances that transport equipment travel on the farm (e.g. for collecting bales), a winding factor of 1.2 , a temperature $\left(-20^{\circ} \mathrm{C}\right)$ below which field operations are stopped, grain yield (185 bu/ac), equivalent biomass yield $(4.38 \mathrm{dt} / \mathrm{ac})$, conservation allowance $(0.715$ $\mathrm{dt} / \mathrm{ac})$, maximum moisture content for baling $(0.17 \mathrm{wb})$, initial moisture content of biomass at the start of harvest $(0.40 \mathrm{wb})$, number of days allowed for biomass to stay in the field (if biomass does not dry within this time frame, then the biomass is baled at its moisture content), the amount of biomass after completion of the harvest $(850,000 \mathrm{dt}$ ), and the amount of initial biomass (before harvest 1,451,665 $\mathrm{dt})$. The initial biomass tonnage $(1,451,665 \mathrm{dt})$ and associated acres required were estimated by trial and error in order to yield a tonnage near to the $850,000 \mathrm{dt}$ that is required for an annual supply to a biorefinery. The required initial biomass tonnage was estimated from the ratio of the final yield to initial yield per acre (2.58/4.38) as explained further in the following paragraph.

Table 14. List of input parameters related to simulation of collecting stover using the IBSAL model

\begin{tabular}{|c|c|c|}
\hline Parameter & value & Description \\
\hline Number of item (land) units & 1000 & Item numbers for simulation \\
\hline Land Unit size (ac) & 335 & Land unit size for simulation purposes \\
\hline $\mathrm{x}$-coordinate minimum (miles) & 0.1 & $\begin{array}{l}\text { Coordinates relate to the distance the equipment travel on the } \\
\text { farm }\end{array}$ \\
\hline $\mathrm{x}$-coordinate maximum (miles) & 1.0 & $\begin{array}{l}\text { Coordinates relate to the distance the equipment travel on the } \\
\text { farm }\end{array}$ \\
\hline y-coordinate minimum (miles) & 0.1 & $\begin{array}{l}\text { Coordinates relate to the distance the equipment travel on the } \\
\text { farm }\end{array}$ \\
\hline y-coordinate maximum (miles) & 1.0 & $\begin{array}{l}\text { Coordinates relate to the distance the equipment travel on the } \\
\text { farm }\end{array}$ \\
\hline Winding Factor & 1.2 & Deviation from a straight line \\
\hline Critical temperature $\left({ }^{\circ} \mathrm{C}\right)$ & -20 & The temperature below which the operations are stopped \\
\hline Average grain yield (bu/ac) & 185 & Average grain yield. \\
\hline Biomass to grain ratio & 1.0 & $\begin{array}{l}\text { Above ground biomass weight to the weight of grain (dry } \\
\text { weight basis) }\end{array}$ \\
\hline Average biomass yield ( $\mathrm{dt} / \mathrm{ac})$ & 4.38 & Average biomass yield for the location (based on grain yield) \\
\hline $\begin{array}{l}\text { Yield to be deducted for } \\
\text { conservation allowance }\end{array}$ & 0.715 & (Gallagher et al. 2003) \\
\hline Net Yield & 3.665 & $\begin{array}{l}\text { Net yield that can be removed after meeting conservation } \\
\text { allowance }\end{array}$ \\
\hline Critical safe moisture content & 0.17 & $\begin{array}{l}\text { Critical safe moisture content which delays baling until biomass } \\
\text { is below this moisture }\end{array}$ \\
\hline $\begin{array}{l}\text { Initial grain moisture content } \\
\text { (Decimal fraction wb) }\end{array}$ & 0.40 & $\begin{array}{l}\text { Initial moisture content is an estimate of the initial moisture } \\
\text { content of grain }\end{array}$ \\
\hline $\begin{array}{l}\text { Maximum number of days } \\
\text { allowed for field drying }\end{array}$ & 5 & $\begin{array}{l}\text { Maximum number of days allowed to leave biomass on field } \\
\text { before baling }\end{array}$ \\
\hline Mass required $(\mathrm{dt})$ & 850,000 & The desired quantity of biomass in storage \\
\hline Initial mass (dry matter) & $1,451,665$ & $\begin{array}{l}\text { The initial biomass needed to yield the required biomass to be } \\
\text { input to the biorefinery }\end{array}$ \\
\hline
\end{tabular}


IBSAL used a random distance generated between maximum and minimum straight line distance to calculate the distance traveled for the collection equipment. For this example, IBSAL used a Stinger (http://www.stingerltd.com) that is a self load/unload bale collector and stacker made by Stinger Ltd. For simulation purposes, IBSAL generated 1000 items. The size of each item (335 ac) was calculated by dividing the initial tonnage (1,451,665 dt by gross yield 4.38 and 1000 items). IBSAL divided these arbitrarily chosen 1000 items (land units) into daily items to simulate the progress of harvest. A larger number of items with smaller size acreage increase the computing time. A smaller number of items, using larger land unit sizes, increase inaccuracies in estimating the completion dates and the size of infrastructure (number of equipment and storage space).

Tables 15 and 16 list calculated values taken from IBSAL output. Column 1 of Table 15 lists sequence of simulated operations (equipment). Ten percent of the combine cost was allocated for biomass harvest, resulting in $\$ 1.75 / \mathrm{dt}$ for biomass harvest. The cost of the shredder was $\$ 1.16 / \mathrm{dt}$ and the cost of a tractor to pull the shredder was $\$ 3.21 / \mathrm{dt}$. Similarly for baling $\$ 8.46 / \mathrm{dt}$ was for the baler and $\$ 7.41 / \mathrm{dt}$ was for the pulling tractor. Other listed cost items are for the Stinger to transport bales to the side of the farm $(\$ 2.50 / \mathrm{dt})$, and a loader to place bales on the wrapper $(\$ 0.72 / \mathrm{dt})$. Wrapping, including the cost of the wrap material, was $\$ 6.05 / \mathrm{dt}$. The cost of storing bales was $\$ 2.58 / \mathrm{dt}$ including the cost of land occupied by the storage area (see Appendix A).

Cost items in column 2 of Table 15 can not be summed because tonnage decreases after each operation (due to dry matter loss). Column 3 lists cumulative costs. The overall cost of collecting, wrapping, and storing biomass bales is the last entry, $\$ 40.15 / \mathrm{dt}$. The costs in column 2 are calculated from an overall $\$ / \mathrm{hr}$ based on assuming an annual number of working hours for the machine. These costs represent a situation where a biomass producer hires a custom operator to perform the operation at a specified $\$ / \mathrm{hr}$ (custom) rate.

Table 15. Summary of the cost of harvesting, wrapping, and stacking stover bales

\begin{tabular}{|c|c|c|c|c|c|c|c|}
\hline 1 & 2 & 3 & 4 & 5 & 6 & 7 & 8 \\
\hline Operation & $\begin{array}{c}\text { Cost } \\
(\$ / d t)^{a}\end{array}$ & $\begin{array}{c}\text { Cumul- } \\
\text { ative } \\
\text { cost } \\
(\$ / d t)\end{array}$ & $\begin{array}{c}\text { Fixed cost } \\
(\$ / y \mathbf{y r})\end{array}$ & $\begin{array}{c}\text { Variable } \\
\text { cost } \\
(\$ / y r)\end{array}$ & $\begin{array}{c}\text { Ownership } \\
(\$ / y r)\end{array}$ & $\begin{array}{l}\text { Number of } \\
\text { machines }\end{array}$ & $\begin{array}{c}\text { Total } \\
\text { purchase } \\
\text { cost } \\
(\$)\end{array}$ \\
\hline Harvestable & 0.00 & 0.00 & 0 & 0 & 0 & 0 & 0 \\
\hline Combine $^{\mathrm{b}}$ & 1.75 & 1.75 & 176,072 & $1,914,416$ & $2,090,487$ & 150 & $30,970,000$ \\
\hline Shredder & 1.16 & 3.05 & 103,357 & $1,041,582$ & $1,144,938$ & 70 & $2,117,942$ \\
\hline Tractor & 3.21 & 6.26 & 560,838 & $3,582,593$ & $4,143,431$ & 70 & $10,842,930$ \\
\hline Baler & 8.46 & 15.64 & 694,120 & $5,891,467$ & $6,585,587$ & 110 & $12,825,010$ \\
\hline Tractor & 7.41 & 23.06 & 881,316 & $7,209,834$ & $8,091,151$ & 110 & $17,038,890$ \\
\hline Stinger & 2.50 & 26.20 & 187,008 & $2,165,076$ & $2,352,084$ & 26 & $3,462,836$ \\
\hline Bale loader & 0.72 & 27.11 & 137,231 & 660,738 & 797,970 & 40 & $2,660,440$ \\
\hline Bale wrap & 6.05 & 33.29 & 83,019 & 923,167 & $1,006,186$ & 40 & $1,533,080$ \\
\hline Storage & 2.58 & 40.15 & $2,186,635$ & 0 & $2,186,635$ & 1 & $18,659,757$ \\
\hline Total & & 40.15 & $5,009,596$ & $23,388,874$ & $28,398,470$ & & $100,110,885$ \\
\hline
\end{tabular}

adt is dry ton

${ }^{b} 10 \%$ of the grain harvest cost 
The dollar values in columns 4 and 5 are total annual fixed costs and variables costs. The variable costs are calculated from variable $\$ / \mathrm{hr}$ costs multiplied by the actual number of hours for the equipment to complete the operation (this is different from the numbers in column 2 where a fixed number of operating hours are assumed for the machine). Column 6 lists the sum of columns 4 and 5 . This sum may be considered as an ownership rate where a biomass producer owns the machine. The ownership rate is calculated from dividing total fixed and variable costs (column 6) by total annual delivered tonnage $(\$ 28,398,470 / 851,080=\$ 33.37)$. This $\$ 33.37 / \mathrm{dt}$ ownership rate is lower than the $\$ 40.15 / \mathrm{dt}$ custom rate because for the ownership rate the variable costs represent actual hours of use that, in some cases, are more than the number of fixed hours assumed for calculating custom rates. Column 7 shows the minimum number of equipment to complete the harvest in 71 days (Table 16). Column 8 lists the total purchase cost for new equipment. The initial investment is $\$ 100,110,885$.

Column 2 in Table 16 lists the number of days needed to complete the harvest. To arrive at this number of days, the number of equipment for each operation (Table 15) was adjusted manually. Biomass harvest was scheduled to be completed in 71 days. Table 16 also lists energy input and carbon emissions from powered equipment (tractors and self-powered equipment). IBSAL calculates 435,010 Btu equivalent energy input per dt of harvested biomass. The energy input (expenditure) is roughly $2.9 \%$ of the energy content of a dt of processed biomass (15 million Btu/dt). Tractors that pull shredders and balers consume the most energy, followed by Stinger. In this model $10 \%$ of the combine power is allocated to the power used for biomass harvest. The corresponding emitted carbon was $22.77 \mathrm{lb} \mathrm{C} / \mathrm{dt}$ of biomass.

Table 16. Summary of other useful output of IBSAL for harvesting, wrapping, and stacking stover bales

\begin{tabular}{|c|c|c|c|c|c|c|c|}
\hline 1 & 2 & 3 & 4 & 5 & 6 & 7 & 8 \\
\hline Operation & $\begin{array}{c}\text { No. of } \\
\text { working } \\
\text { days }\end{array}$ & $\begin{array}{c}\text { Energy } \\
(\mathbf{M B t u} / \mathbf{d t})^{\mathrm{a}}\end{array}$ & 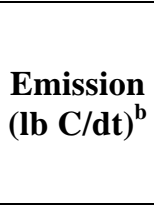 & $\begin{array}{l}\text { Total mass } \\
\quad(d t)\end{array}$ & $\begin{array}{c}\text { Queue } \\
\text { dry } \\
\text { matter } \\
\text { loss (dt) }\end{array}$ & $\begin{array}{c}\text { Mach. } \\
\text { dry } \\
\text { matter } \\
\text { loss } \\
\text { (dt) }\end{array}$ & $\begin{array}{c}\text { Net yield } \\
\text { (dt/ac) }\end{array}$ \\
\hline Harvestable & 0 & 0.00 & 0.00 & $1,451,665$ & 0 & 0 & 4.38 \\
\hline Combine $^{c}$ & 60 & 18.22 & 0.95 & $1,233,915$ & 0 & 217,750 & 3.72 \\
\hline Shredder & 58 & 0.00 & 0.00 & $1,144,535$ & 66,022 & 23,358 & 3.45 \\
\hline Tractor & 58 & 71.26 & 3.73 & $1,144,535$ & 0 & 0 & 3.45 \\
\hline Baler & 63 & 0.00 & 0.00 & 998,324 & 39,988 & 106,223 & 3.01 \\
\hline Tractor & 63 & 162.67 & 8.51 & 998,324 & 0 & 0 & 3.01 \\
\hline Stinger & 69 & 33.69 & 1.76 & 971,303 & 7,521 & 19,500 & 2.93 \\
\hline Bale loader & 19 & 8.18 & 0.42 & 964,802 & 1,732 & 4,769 & 2.91 \\
\hline Bale Wrap & 71 & 5.27 & 0.27 & 960,057 & 0 & 4,745 & 2.90 \\
\hline Storage & - & 0.00 & 0.27 & 851,080 & 108,977 & 0 & 2.58 \\
\hline Total (Overall) & & 435.01 & 22.77 & 851,080 & 224,241 & 376,345 & \\
\hline
\end{tabular}

${ }^{\mathrm{a}} \mathrm{MBtu}$ is $1000 \mathrm{Btu}$

${ }^{\mathrm{b}} \mathrm{dt}$ is dry ton

${ }^{\mathrm{c}} 10 \%$ of total energy input and carbon emission

The dry matter loss is of particular importance for the biomass in queue (dry matter loss while biomass lies in the field or in a queue waiting to be handled). The initial dry mass is 1,451,665 dt. The equivalent yield for this quantity of biomass is $4.38 \mathrm{dt} / \mathrm{ac}$. At the conclusion of the last operation, $851,080 \mathrm{dt}$ or roughly $58 \%$ of the original biomass is available in storage. Dry mass losses reduce the amount by $224,341 \mathrm{dt}$ in storage (and in queue) and 376,345 dt in operations. The net yield is 2.58 dt/ac. Manual calculations show that $99 \%$ (from Table 13) of the 1000 land units (items) of 335 ac 
each amounts to a harvested area of 331,650 ac. The final 848,027 dt represent a net yield of 2.56 $\mathrm{dt} / \mathrm{ac}$. This is within $0.02 \mathrm{dt} / \mathrm{ac}$ of the IBSAL calculated value at $2.58 \mathrm{dt} / \mathrm{ac}$.

\subsection{TRANSPORTATION}

For a transportation example, IBSAL supplies $850,000 \mathrm{dt}$ of biomass from distributed storage sites (stacks) to a biorefinery. The distances from storage sites to biorefinery vary from 1 to 100 miles. Delivery takes place over the entire year, with an equal number of loads per day. Table 17 lists logistical inputs to IBSAL for modeling the transport example. Some of the values are user defined inputs and some are calculated by Excel and used as input to IBSAL. The calculated values are daily tonnage to be transported, number of stores serviced per day, number of discrete items per store, total mass of discrete items in a year (this is calculated by multiplying number of discrete items per store times number of stores per day times number of days in a year times mass per discrete item), and 3day storage capacity at the biorefinery.

Figure 10 is the image of the IBSAL modules linked to represent the transport of bales from distributed storage (stacks) sites to the refinery. The suite of equipment used for transportation includes two bale loaders; one to load bales on a flat bed trailer at the stack and another to unload and restack bales at the refinery. The storage site at the refinery is a paved yard. The image in Figure 10 shows that there could be delays in loading bales on the trailer tractor at the farm site due to precipitations (rain or snow or cold temperatures). Appendix A lists the specifications for equipment and the storage site.

Table 17. Input to the IBSAL transportation example

\begin{tabular}{lrl}
\hline \multicolumn{1}{c}{ Parameter } & Value & Remarks \\
\hline Annual mass demand (dt) & 850,000 & Annual biomass supply to ethanol plant \\
Capacity of each supply store (dt) & 400 & Tonnage in each stack consisting of 800 bales \\
Number of days in a year & 313 & Annual number of days for biomass delivery, six days a week \\
Mass demand per day (dt) & 2,716 & Annual supply divided by number of days \\
Number of stores serviced per day & 7 & Number of stack locations that will be serviced in a day. \\
Mass in a discrete item (dt) & 100 & Discrete item size (tonnage) for IBSAL simulation \\
Number of discrete item per store & 4 & Number of discrete items per stack. \\
Max distance (mile) & 100 & Maximum distance to transport biomass to the plant \\
Min distance (mile) & 1 & Minimum distance to transport biomass to the plant \\
Winding factor & 1.4 & Multiplier to compensate for roadways \\
Start day (Julian) & 240 & Day of the year that biomass delivery starts \\
MC initial (dec wb) & 0.15 & Initial moisture content of biomass in the stack \\
Number of discrete items & 8,764 & Number of simulation items \\
Annual mass supplied (dt) & 876,400 & Total tonnage when all the simulated items are serviced \\
Storage capacity for 3 days (at & 7,286 & Storage capacity at the plant for three days of storage \\
refinery) (dt) & &
\end{tabular}




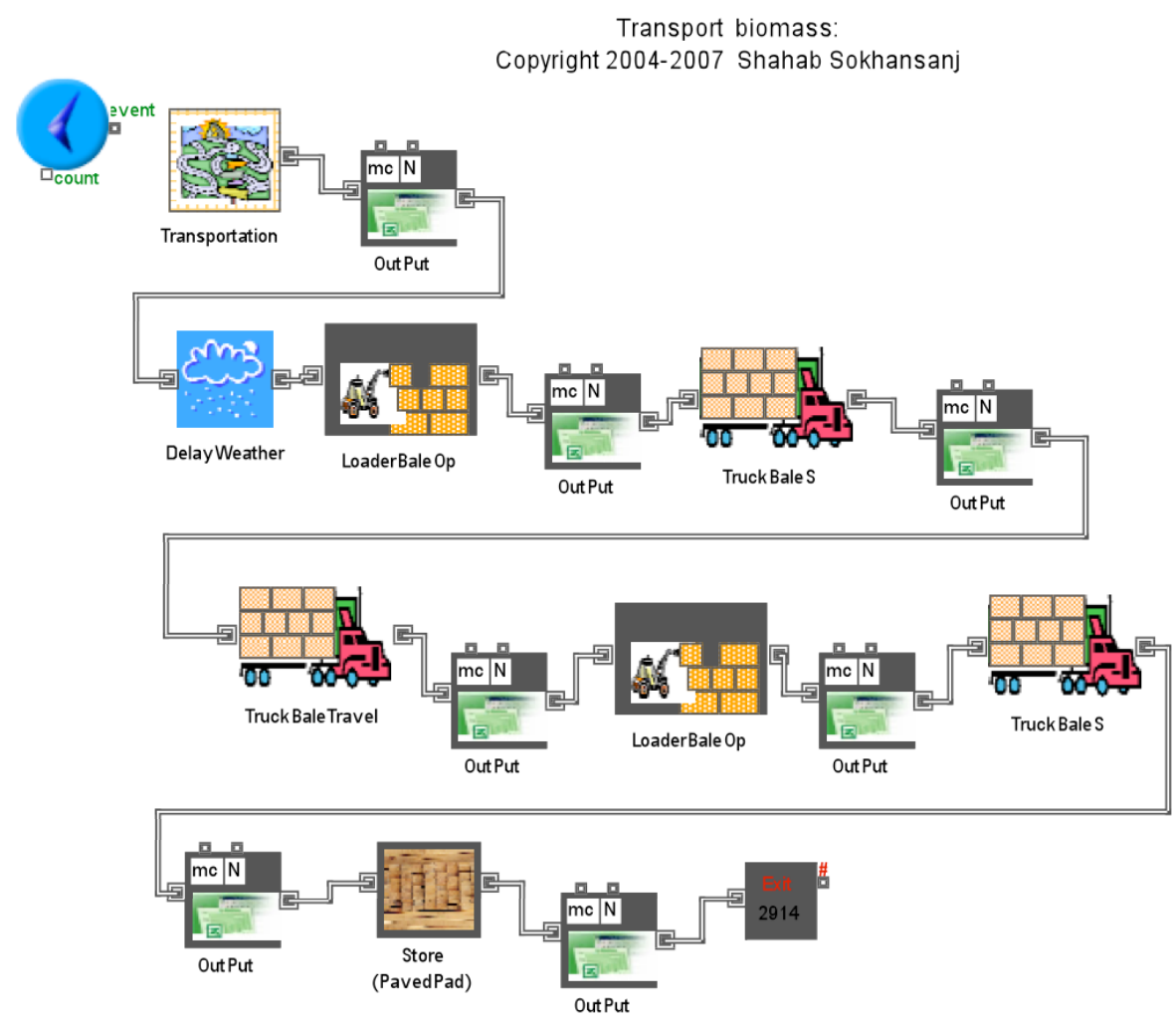

Figure 10. An image of IBSAL with operations for transporting bales from distributed storage (stack) sites to a biorefinery where the bales are restacked on a paved yard

Table 18 is a summary of the IBSAL output, simulating the transport of biomass. For this simulation the distance has a uniform random distribution with a minimum of 1 mile and a maximum of 100 miles. The total cost of transport is $\$ 21.03 / \mathrm{dt}$, out of which the actual travel cost is the largest fraction at $\$ 11.66 / \mathrm{dt}$. The bales are stacked on paved area at the biorefinery at an estimated cost at $\$ 6.70 / \mathrm{dt}$. For loading, $\$ 0.92 / \mathrm{dt}$ is for telescopic bale handler (loader) and $\$ 0.40$ is for the truck waiting to be loaded. For unloading, $\$ 0.74 / \mathrm{dt}$ is for the telescopic bale handler (loader) and $\$ 0.40 / \mathrm{dt}$ is for the truck waiting to be unloaded. The minimum number of equipment for uniform delivery of biomass six days a week to the biorefinery consists of 16 loaders at the loading sites, 240 trucks, and 14 loaders at the biorefinery for unloading. The total investment, including the cost of preparing the 3-day storage area at the biorefinery, is $\$ 37,816,530$.

The total energy input is more than $1,508,780 \mathrm{Btu} / \mathrm{dt}$. Trucks require the most energy input $(1,187,950 \mathrm{Btu} / \mathrm{dt}$ ) due to a long travel distance (between 1 to $100 \mathrm{miles})$. Carbon emissions followed the energy consumption with a total of $78.94 \mathrm{lb} \mathrm{C} / \mathrm{dt}$. The model also predicted roughly a $2.6 \%$ reduction in biomass tonnage delivered to the plant. This reduction is due to time spent on the truck. Transport time includes loading and unloading operations. The losses reported here are timedependent losses. The loading and unloading times were insignificant compared to travel time. Physical losses for transport, loading and unloading operation were assumed to be zero. Table 18 shows that out of $864,746 \mathrm{dt}$ of biomass loaded at the stacks $842,044 \mathrm{dt}$ arrived at the biorefinery. The difference of $22,702 \mathrm{dt}$ or $2.6 \%$ of the original tonnage was lost during handling. Further trial and error is required to increase the delivered tonnage to $850,000 \mathrm{dt}$ of the annual demand. 
Table 18. IBSAL output for transporting biomass from distributed storage sites to a biorefinery

\begin{tabular}{lccccccc}
\hline $\begin{array}{c}\text { Operation } \\
\text { lequipment }\end{array}$ & $\begin{array}{c}\text { Cost } \\
\mathbf{( \$ / d t )}\end{array}$ & $\begin{array}{c}\text { Cum. cost } \\
\mathbf{( \$ / d t )}\end{array}$ & $\begin{array}{c}\text { Energy } \\
(\mathbf{M B t u} / \mathbf{d t})\end{array}$ & $\begin{array}{c}\text { Emission } \\
(\mathbf{l b ~ C / d t )}\end{array}$ & $\begin{array}{c}\text { Mass } \\
(\mathbf{d t})\end{array}$ & $\begin{array}{c}\text { No. } \\
\text { equip. }\end{array}$ & $\begin{array}{c}\text { Investment } \\
\mathbf{\$}\end{array}$ \\
\hline Loader & 0.92 & 0.92 & 8.22 & 0.43 & 864,746 & 16 & $1,064,176$ \\
Truck load & 0.40 & 1.32 & 142.05 & 7.43 & 860,422 & - & 0 \\
Truck Transport & 11.66 & 12.99 & 1187.95 & 62.15 & 855,140 & 240 & $35,821,200$ \\
Un-loader & 0.74 & 13.87 & 8.22 & 0.43 & 846,395 & 14 & 931,154 \\
Truck unload & 0.40 & 14.33 & 162.34 & 8.49 & 842,163 & - & 0 \\
Store & 6.70 & 21.03 & 0.00 & 8.49 & 842,044 & 1 & 417,741 \\
Total & & 21.03 & 1508.78 & 78.94 & 842,044 & - & $37,816,530$ \\
\hline
\end{tabular}

\section{SENSITIVITY ANALYSIS}

IBSAL is capable of investigating the sensitivity of key parameters to the elements that influence a biomass supply system. The following subsections provide examples of analyses of major factors, such as location (weather), crop yield, initial harvest moisture content, and in-field transport distances on the cost and other output parameters. Appendix A lists the base (optimum) yields, optimum speeds, and efficiencies for equipment used in the sensitivity analysis.

\subsection{LOCATION}

Climate and progress of harvest are among key parameters influencing availability of biomass. Figure 11 compares the quantity of biomass and the collection cost of stover in three locations, Des Moines, Iowa, Lubbock, Texas, and Lansing, Michigan. IBSAL uses harvest season conditions for Des Moines as the base case (Table 1). All input data for Lansing and Lubbock remain the same as for Des Moines except for weather data and progress of harvest. Data in Table 1 shows that in Des Moines $94 \%$ of the harvest was completed, whereas in Lubbock $100 \%$ of the harvest was completed and in Lansing only $74 \%$ of the harvest was completed in the same year (2005 harvest season).

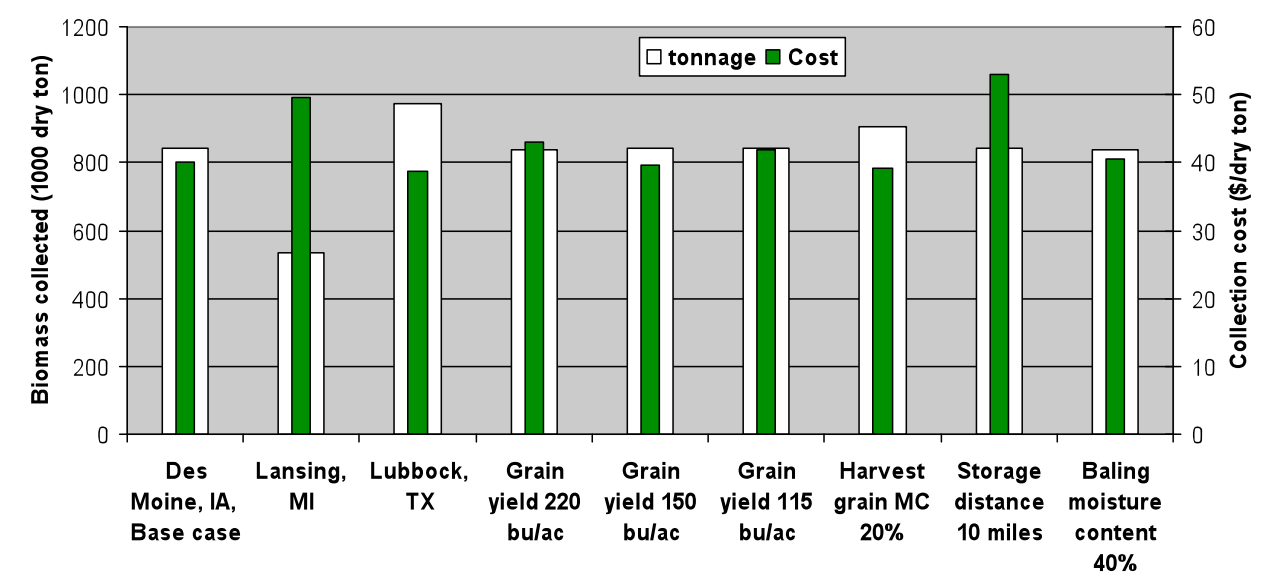

Figure 11. Sensitivity of cost of biomass collection and the quantity of biomass collected to several variables 
Harvested biomass at Des Moines was 840,000 dt (white bar) compared with Lubbock at 972,000 dt and Lansing at 534,000 dt (Figure 11). The cost of collection at Des Moines was $\$ 40 / \mathrm{dt}$ compared to $\$ 50 / \mathrm{dt}$ at Lansing and \$38/dt at Lubbock TX. The in-queue and storage dry matter losses (does not include dry matter losses due to equipment operation) for the base case in Des Moines was 6.8\%, for Lansing was $8.6 \%$, and for Lubbock was $2.5 \%$ (data not shown).

\subsection{SENSITIVITY TO YIELD}

Figure 11 shows the sensitivity of production cost and the quantity of biomass harvested to grain yield (and hence biomass yield). The yield for the base case in Des Moines was $185 \mathrm{bu} / \mathrm{ac}$. The other three yields for Des Moines were 220, 150, and 115 bu/ac. The bar graphs for yields in Figure 11 show little variation in the total biomass produced as expected (i.e. IBSAL adjusts speed to compensate for variation in biomass yield). The cost increases slightly on both sides of $150 \mathrm{bu} / \mathrm{ac}$. This is due to reduction in equipment operating efficiency as the yield deviates from $150 \mathrm{bu} / \mathrm{ac}$.

\subsection{SENSITIVITY TO INITIAL HARVEST MOISTURE CONTENT}

The initial harvest moisture content of the grain in the base case was $40 \%$ (wb). A reduction in the initial moisture content of grain to $20 \%$ resulted in an increase in biomass availability and a slight reduction in cost. Harvest of grain at $40 \%$ moisture is rare and is limited only to northern cool and humid regions, such as Michigan. It is expected that most grain is harvested below 25\% moisture content. The moisture content of biomass though remains high at a grain moisture content of $25 \%$ (see figures 3 and 4 ).

Figure 11 also shows the effect of variation in the specified moisture content of biomass for baling. For this particular sensitivity analysis case, increasing the specified moisture content of biomass for baling from $17 \%(\mathrm{wb})$ to $40 \%$ (wb) slightly increased the cost, but the increase in the specified moisture content did not result in an appreciate change in the availability of biomass. In this example, the storage dry matter losses were minimal because bales (high moisture or low moisture) were wrapped.

\subsection{SENSITIVITY TO IN-FIELD TRANSPORT DISTANCE}

For the base case, biomass was stacked next to the farm at a distance that ranged from 0.1 to 1 mile in each direction ( $\mathrm{x}$ and $\mathrm{y}$ ). Figure 11 shows the base case compared to a case when the maximum distance in each direction was increased to 7 miles (or approximately 10 mile straight line transport). The cost increased significantly from around $\$ 40 / \mathrm{dt}$ to more than $\$ 52 / \mathrm{dt}$. The increase in cost was due to the increased travel distance. Travel distance does not affect the quantity of collected biomass provided the number of transport equipment is optimized to meet the harvest and storage schedule. In other words, increase in storage time due to a shortage of transport equipment results in increased dry matter loss and increased costs.

\section{CONCLUSIONS}

This document describes the development of a dynamic simulation model of biomass collection and transport. The model is called IBSAL for Integrated Biomass Supply Analysis \& Logistics. The model uses mathematical equations to simulate the operating performance of an assembly of 
equipment subject to constraints imposed on the supply chain by weather. Mathematical models are also developed to calculate the moisture content of biomass during handling and dry matter loss due to mechanical handling and while biomass waits in a queue or in storage. A standard costing method is implemented to estimate the cost of harvest and post harvest handling, including transportation. The model also calculates energy consumption and carbon emissions for power equipment. The mathematical models are programmed on a dynamic simulation package Extend v.6 (www.imaginethatinc.com). Excel worksheets are used as means of entering input to the model and receiving output from the model.

The model was applied to collection and transport of corn stover for the State of Iowa (Des Moines). Typical Meteorological Year Data (TMY2) and progress of harvest from the USDA-NASS Website were used as input to the model. A sequence of operations consisting of shredding/swathing, baling, and stacking was used. The square bales were wrapped in plastic sheets to protect the bales from weathering. The stacks of bales were placed next to each farm. The farms were spread out randomly around a biorefinery. The distance between farms and biorefinery ranged from 1 to 100 miles. Flat bed truck trailers were used to transport bales to the biorefinery. The delivery took place 14 hours a day, six days a week for the entire year. For both harvest and transport modeling, the number of equipment was adjusted manually for each simulation in order to meet harvest and delivery schedules.

The model calculated the cost of collecting and storing biomass at $\$ 40.15 / \mathrm{dt}$ in Iowa, $\$ 38.65 / \mathrm{dt}$ in Texas, and \$49.54/dt in Michigan. The net amount of stover collected during the harvest season in Iowa (base case) was roughly 851 thousand dt. In Texas the same land area as in Iowa provided 972 thousand dt and in Michigan 534 thousand dt. For Iowa, the energy input for power equipment amounted to 435 thousand Btu per collected dt emitting $22.77 \mathrm{lb}$ of $\mathrm{C} / \mathrm{dt}$. The gross yield of $4.38 \mathrm{dt} / \mathrm{ac}$ dropped to a net yield of $2.58 \mathrm{dt} / \mathrm{ac}$ at the end of the collection sequence. The initial dry mass of $1,451,665 \mathrm{dt}$ was reduced to $851,080 \mathrm{dt}$ ( $41.3 \%$ loss). A sum of $224,241 \mathrm{dt}$ ( $15.4 \%$ of the original) was lost in queue plus in storage and a sum of 376,345 (25.9\% of the original) dt was lost due to machinery operation. These losses were roughly $41 \%$ of the original mass.

The average cost of transporting roughly $850,000 \mathrm{dt}$ biomass was calculated to be $\$ 21.03 / \mathrm{dt}$. The transport distance varied from 1 to 100 mile. Provisions were made for three day storage of bales on paved pad at the plant. The largest cost was that of truck transport that was $\$ 11.66 / \mathrm{dt}$. Stacking and storage cost at the plant cost $\$ 6.70 / \mathrm{dt}$. On a per dt basis, the energy consumption for transport (1509 $\mathrm{MBtu} / \mathrm{dt}$ ) was six time higher than those for harvest (235 MBtu/dt). Truck transport was the major energy user. The model calculated roughly a $2.6 \%$ dry matter loss during handling and transport.

\section{RECOMMENDATIONS}

The IBSAL model developed and described in this document is based on the first author's experience with handling agricultural materials and products from grain, feed, and forage. Much of the data that is needed to develop constants for equations is not available for different biomass species. The following further research is needed to collect data that can be used in improving the model. The data will also be useful in reducing uncertainties in establishing biorefineries that require biomass feedstocks.

- A relationship between moisture content of grain and moisture content of stalks for various corn varieties and grain species under different cultural practices. 
- Data on progress of crop harvest for locations within a state; the existing statewide USDA data on of harvest progress are too coarse.

- Regional moisture content of grain at the time when grain harvest commences for the region.

- Drying rate (moisture content vs. time) and moisture absorption rate for biomass at different stages of handling (standing crop, after combining, shredded and spread, windrowed, baled, during storage).

- Dry matter loss of biomass while in queue or in storage in various environmental conditions. Relating the dry matter loss to the geometry of individual bales, and the entire stack.

- Dry matter loss during equipment operation as a function of moisture content of biomass.

- Relationships among equipment specifications (e.g. width of cut) and operational parameters (speed, efficiency) and crop density (yield) for harvest and collection equipment. 


\section{REFERENCES}

AAEA. 2000. Commodity costs and returns estimation handbook. American Agricultural Economics Association, Ames, IA.

Andrews, S. 2006. Crop residue removal for biomass energy production: effects on soils and recommendations. White paper. Soil Quality Technology Development Team. USDA-Natural Resource Conservation Service. http://soils.usda.gov/sqi/management/files/AgForum_Residue_White_Paper.pdf (accessed 2008-01-04).

ASABE. 2006a. Standards. ASAE D245.5 OCT1995, Moisture relationships of plant-based agricultural products. American Society of Agricultural Engineers, St. Joseph, MI 490859659 .

ASABE. 2006b. Standards. ASAE D497.5 FEB2006, Agricultural machinery management data. American Society of Agricultural and Biological Engineers, St. Joseph, MI. 49085-9659.

ASABE. 2006c. Standards. ASAE EP496.3 FEB2006, Agricultural machinery management. American Society of Agricultural Engineers, St. Joseph, MI 49085-9659.

Bern, C.J., J.L. Steele, and R.V. Morey. 2002. Shelled corn CO2 evolution and storage time for 0.5\% dry matter loss. Applied Engineering in Agriculture 18(6):703-706.

Blunck, S.L., M.W. Yore, M.D. Summers, G.K. Lau, S.T. Tang, and B.M. Jenkins. 2003. Quality and property changes in rice straw during long term storage. ASAE 036091. American Society of Agricultural Engineers, St. Joseph, MI 49085-9659.

Buckmaster, D.R. 1990. Forage losses = economic losses, so minimize them. Publication I-107. College of Agriculture, Agricultural and Biological Engineering. Penn State University, University Park, PA.

Colley, Z., O.O. Fasina, D. Bransby, and Y.Y. Lee. 2006. Moisture effect on the physical characteristics of switchgrass pellets. Transactions of the ASABE 49(6):1845-1851.

Cross, T.L. and G.M. Perry. 1995. Depreciation patterns for agricultural machinery, American Journal of Agricultural Economics 77:194-204.

Cross, T.L. and G.M. Perry. 1996. Remaining value functions for farm equipment, Applied Engineering in Agriculture 12:547-553.

DOE. 2003. Roadmap for Agriculture Biomass Feedstock Supply in the United States. DOE/NE-ID11129Rev0. 102 pages.

Extend. 2003. Users guide. Ver. 6.x Imagine That Inc., San Jose, CA.

Fraser, B.M. and W.E. Muir. 1981. Airflow requirements predicted for drying grain with ambient air and solar-heated air in Canada. Transactions of the ASAE 24(1):208-210.

Gallagher, P., M. Dikeman, J. Fritz, E. Wailes, W. Gauther, and H. Shapouri. 2003. Biomass from crop residues: cost and supply estimates. Publication AER-819, Office of Energy Policy and New Uses, USDA, Washington DC.

Holman, J.P. 1990. Heat Transfer. Seventh Edition. McGraw-Hill Publishing Co., New York, NY.

Hunt, D.R. 1986. Engineering models for agricultural production. The AVI Pub. Co. Inc., Westport, CT.

Igathinathane, C., A. R. Womac, S. Sokhansanj, L. O. Pordesimo. 2005. Sorption Equilibrium moisture characteristics of selected corn stover components. Transactions of the ASAE 48(4):1449-1460.

Igathinathane, C., A. R. Womac, S. Sokhansanj, L. O. Pordesimo. 2006. Mass and moisture distribution in above ground components of standing corn plant. Transactions of the ASAE 49(1):97-106. 
Igathinathane, C., A. R. Womac, L. O. Pordesimo , S. Sokhansanj. 2008. Mold appearance and modeling on selected corn stover components during moisture sorption. Bioresource Technology (2008), Available on-line doi:10.1016/j.biortech.2007.11.075.

Jenkins, B.M. 2005. Biomass resources in California - quantities, availability, and costs of supply. Special presentation at the 2005 AETC Louisville Kentucky Feb 12-14. University of California, Davis, CA.

Krahl, D. 2001. The Extend simulation environment. Proceedings of the 2001 winter Simulation Conference. Peters et al. (ed). Pages 217-225.

Lam, P. S. , S. Mani, M. Hoque, L. Jafari-Naimi, S. Sokhansanj, and X. Bi. 2007. Physical characterization of switchgrass and wheat straw. ASABE paper 076058. American Society of Agricultural Engineers, St. Joseph, MI 49085-9659.

Marion, W. and K. Urban 1995. User's manual for TMY2 Typical meteorological years derived from the 1961-1990 national Solar Radiation Data base. NREL/SP-463-7668. DE95004064. National Renewable Energy, Golden, CO.

Mantovani B., H.A. Gibson. 1992. Simulation model for analysis of harvesting and transport costs for biomass based on geography, density and plant location. Energy in World Agriculture, Elsevier New York 5:253-280.

Nilsson, D. 1999. Analysis and simulation of systems for delivery of fuel straw to district heating plants. Doctoral thesis. Swedish University of Agricultural Sciences, Uppsala, Sweden.

Peleg, M. 1983. Physical characteristics of food powders. Pages 293-323 in: Physical Properties of Foods (M. Peleg and E.B. Bagley Eds.). AVI Pub. Co., Westport, CT.

Pitt, R.E. 1990. Silage and hay preservation. NRAES-5. Ithaca, NY: Northeast Regional Agricultural Service Cooperative Extension.

Pordesimo, L.O., S. Sokhansanj, and W.C. Eden. 2004. Moisture and yield of corn stover fractions before and after grain maturity. Transactions of the ASAE 47(5):1597-1603.

Prewitt, R.M., M.D. Montross, S.G. McNeill, T.S. Stombaugh, S.A. Shearer, S.F. Higgins, and S. Sokhansanj. 2007. Corn stover availability and collection efficiency using typical hay equipment. Transactions of the ASAE 50(3):705-711.

Richey, C. B., J. B. Liljedahl, and V. L. Lechtenberg. 1982. Corn stover harvest for energy production. Transactions of the ASAE 25(4):834-839,844.

Rotz, C.A. and T.M. Harrigan. 2005. Predicting suitable days for field machinery operations in a whole farm simulation. Applied Engineering in Agriculture 21(4):563-571.

Shinners, K. J., B. N. Binversie, and P. Savoie. 2003. Harvest and storage of wet and dry corn stover as a biomass feedstock. ASAE Paper No. 03-6088. American Society of Agricultural Engineers, St. Joseph, MI 49085-9659.

Shinners, K. J. and B. N. Binversie. 2004. Harvest and storage of wet corn stover biomass. Paper Number: ASAE/CSAE 041159. Presented at the 2004 ASAE/CSAE Annual International Meeting, Fairmont Chateau Laurier, The Westin, Government Centre, Ottawa, Ontario, Canada.

Shinners K.J., G.C. Boettcher, R.E. Muck, P.J. Weimer, and M.D. Casler. 2006. Drying, harvesting, and storage of perennial grasses as biomass feedstock. ASAE Paper 061012. American Society of Agricultural Engineers, St. Joseph, MI 49085-9659

Sokhansanj, S., A. Turhollow, J. Cushman, and J. Cundiff. 2002. Engineering aspects of collecting corn stover for bioenergy. Biomass and Bioenergy 23 (2002):347-355.

Sokhansanj, S. and A. Turhollow. 2002. Baseline cost for corn stover collection. Applied Engineering in Agriculture 18(5):38-43.

Sokhansanj, S. and A. Turhollow. 2004. Biomass densification - cubing operations and costs. Applied Engineering in Agriculture 20(4):495-499. 
Sokhansanj, S., H. Khoshtaghaza, G. J. Schoenau, E. A. Arinze, and L.G. Tabil. 2003. Heat and moisture transfer and quality changes in containerized alfalfa cubes during transport. Transactions of the ASAE 46(2):423-432.

Steele, J. L., R. A. Saul, and W. V. Hukill. 1969. Deterioration of shelled corn as measured by carbon dioxide production. Transactions of the ASAE 12(5):685-689.

Turhollow, A.F. and S. Sokhansanj. 2007. Costs of harvesting, storing in a large pile, and transporting corn stover in a wet form. Applied Engineering in Agriculture 23(4):439-448.

West, T.O. and G. Marland. 2002. A synthesis of carbon sequestration, carbon emissions, and net carbon flux in agriculture: comparing tillage practices in the United States. Agriculture, Ecosystems, and Environment 91:217-232.

Womac, A.R., C. Igathinathane, S. Sokhansanj, and L.O. Pordesimo. 2005. Biomass moisture relations of an agricultural field residue: corn stover. Transactions of the ASAE 48(6):20732083. 


\section{SYMBOLS}

\begin{tabular}{|c|c|}
\hline$A$ & Area of the field processed (ha, ac) \\
\hline$a_{w i}$ & Water activity (decimal fraction) \\
\hline$C$ & Rate of carbon production $(\mathrm{kg} / \mathrm{h}, \mathrm{lb} / \mathrm{hr})$ \\
\hline$C_{r m}$ & Repair and maintenance cost (\$) \\
\hline$d_{i}$ & Number of days for safe storage \\
\hline$d_{i j}$ & Distance $(\mathrm{km}, \mathrm{mi})$ \\
\hline$d m l_{i}$ & Dry matter loss fraction for day $i$ \\
\hline$d m l_{\max }$ & Maximum dry matter loss fraction for day $i$ \\
\hline$D M L_{b}$ & Dry matter loss (mass fraction) for stored bales \\
\hline$D M L_{f}$ & Dry matter loss (mass fraction) for biomass in the field \\
\hline$D M L_{s}$ & Dry matter loss (mass fraction) for silaged biomass \\
\hline$e$ & Efficiency (fraction decimal) \\
\hline$e_{b}$ & Base efficiency for the optimum or base yield \\
\hline$E_{p}$ & Evaporation $(\mathrm{mm} / \mathrm{d})$ \\
\hline$F$ & Diesel fuel consumption (gal/hr, L/h) \\
\hline$F_{c}$ & Fuel and lubricating cost $(\$ / \mathrm{h})$ \\
\hline$G$ & Throughput capacity (dt/hr) \\
\hline$i$ & Day number \\
\hline$i$ & Interest rate (fraction decimal) \\
\hline$I H T$ & Insurance, housing, taxes $(\$)$ \\
\hline$j$ & Week number \\
\hline$h$ & $\operatorname{Hours}(\mathrm{h})$ \\
\hline$k$ & Drying constant $\left(\mathrm{d}^{-1}\right)$ \\
\hline$k$ & Harvest index, ratio of biomass to grain, (decimal fraction) \\
\hline$k$ & Coefficient to account for imperfect bulk fill in the truck \\
\hline$L_{c}$ & Hourly labor cost $(\$ / \mathrm{h})$ \\
\hline$L_{f}$ & Multiplier representing dry matter losses \\
\hline$L$ & Distance (mile) \\
\hline$M$ & Moisture content (decimal fraction dry basis) \\
\hline$M C_{i}$ & Moisture content (decimal fraction, dry mass basis) on day $i$ \\
\hline$M C_{s}$ & Stalk moisture content (fraction decimal wb) \\
\hline$M_{e}$ & Equilibrium moisture content (decimal fraction dry basis) \\
\hline$M C_{g}$ & Grain kernel moisture content (fraction decimal wb) \\
\hline$M_{i}$ & Initial moisture content (decimal fraction dry basis) \\
\hline$M_{i}$ & Internal moisture content (decimal fraction dry basis) \\
\hline$M_{s}$ & Moisture content of stalks (decimal fraction dry basis) \\
\hline$M_{x}$ & External moisture content (fraction decimal dry basis) \\
\hline$M_{w}$ & Wet basis moisture content (fraction decimal) \\
\hline$N_{\text {items }}$ & Number of discrete items used in the discrete model \\
\hline$n$ & Expected life of equipment of building (year) \\
\hline$P$ & Power (hp, kW) \\
\hline$P$ & Initial investment (\$) \\
\hline$P_{i}$ & Daily cumulative fraction of units harvested (decimal) \\
\hline$P_{s}$ & Saturated vapor pressure (inch $\mathrm{Hg}, \mathrm{kPa}$ ) \\
\hline$P_{v}$ & Vapor pressure (inch $\mathrm{Hg}, \mathrm{kPa}$ ) \\
\hline & Mass of product processed $(\mathrm{dt} / \mathrm{hr}, \mathrm{Mg} / \mathrm{h})$ \\
\hline$Q$ & Total mass to be processed (dt, dry Mg) \\
\hline
\end{tabular}




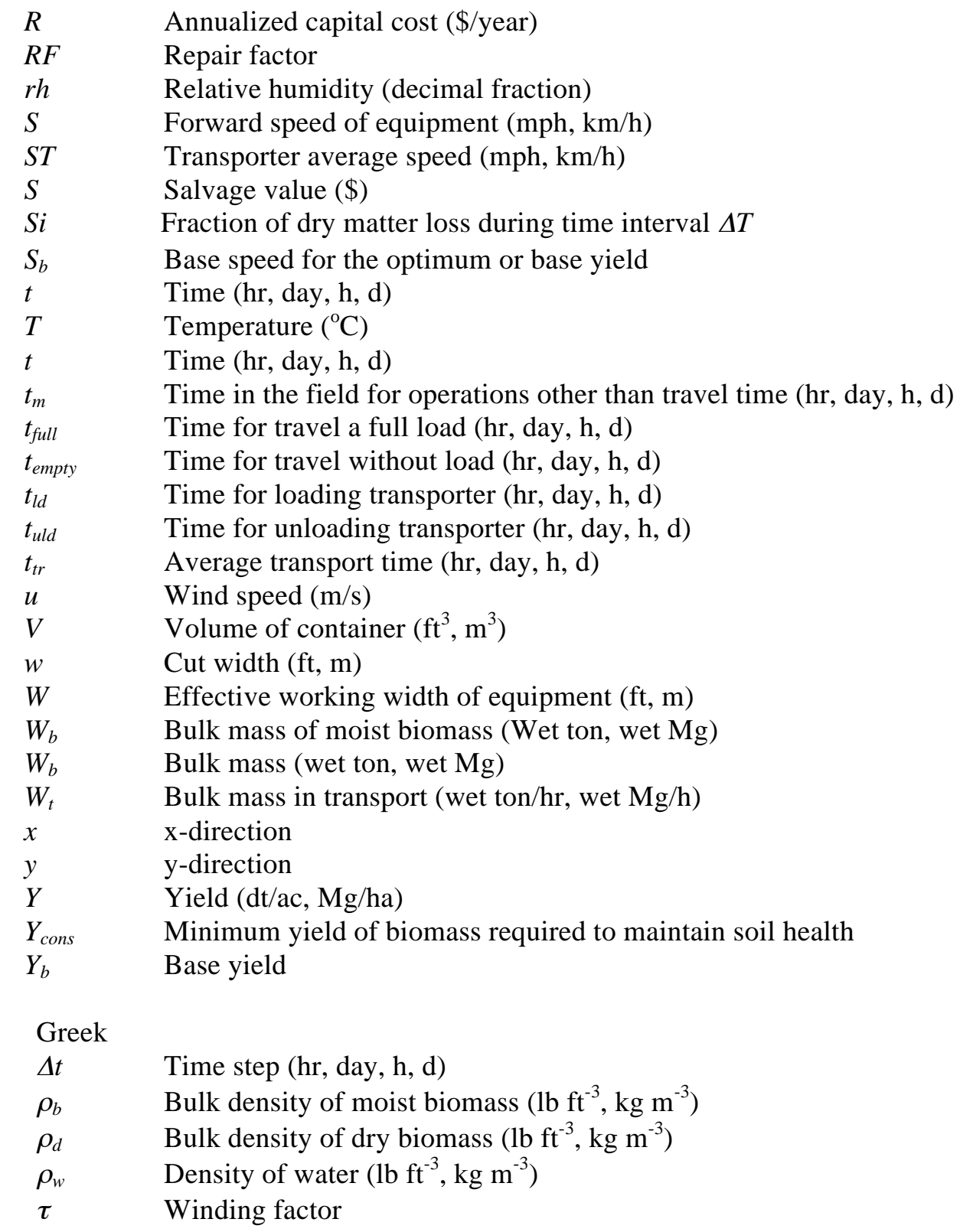




\section{APPENDIX A}

\begin{tabular}{|c|c|c|c|}
\hline \multicolumn{4}{|l|}{ Baler - Rectangular } \\
\hline Bale dimensions (volume $\mathrm{ft}^{3}$ ) $4 \times 4 \times 8$ & 128 & Purchase price & 206,467 \\
\hline Bale density $\left(\mathrm{lb} / \mathrm{ft}^{3}\right)$ & 8 & Grain loss & 0.05 \\
\hline Baling pick up width (ft) & 20 & Biomass loss (includes stubble) & 0.15 \\
\hline Field speed (mph) & 4 & Loss factor & 0.40 \\
\hline Baling efficiency (dec. fraction) & 0.8 & Daily shift (hr/day) & 14 \\
\hline Baler hp requirement $(\mathrm{hp})$ & 275 & Base yield (Bu/ac) & 150 \\
\hline Hours per year & 600 & & \\
\hline Total cost $(\$ / \mathrm{hr})$ & 71.06 & Shredder - Field & \\
\hline Annual fixed cost (\$) & 6310.18 & Width (ft) & 35 \\
\hline Operating cost $(\$ / \mathrm{hr})$ & 60.54 & Speed (mph) & 6 \\
\hline Purchase price & 116,591 & Efficiency & 0.7 \\
\hline Cost of twine per bale ( $\$ /$ bale $)$ & 0.80 & Horsepower (hp) & 225 \\
\hline Biomass loss & 0.10 & Hours per year & 250 \\
\hline Field loss factor & 0.75 & Total cost $(\$ / \mathrm{hr})$ & 27.45 \\
\hline Daily shift (hr/day) & 12 & Annual fixed cost $(\$)$ & 1477 \\
\hline Bale mass $(\mathrm{dt})$ & 0.512 & Operating cost $(\$ / \mathrm{hr})$ & 21.54 \\
\hline \multirow[t]{2}{*}{ Base yield (dt/ac) } & 2.5 & Purchase price & 30,256 \\
\hline & & Biomass loss & 0.02 \\
\hline Stinger - Auto stacker & & Field loss factor & 0.5 \\
\hline Number of bales per load & 8 & Daily shift (hr/day) & 14 \\
\hline Load time per bale (min) & 0.116667 & Base yield $(\mathrm{dt} / \mathrm{ac})$ & 3.19 \\
\hline Unload time per bale (min) & 0.00625 & & \\
\hline Travel speed full (mph) & 30 & Tractor & \\
\hline Travel speed empty (mph) & 30 & Power (hp) & 275 \\
\hline Pickup efficiency (decimal fraction) & 0.9 & Hours per year & 1000 \\
\hline Travel efficiency & 0.9 & Total cost $(\$ / \mathrm{hr})$ & 76.05 \\
\hline Stacking efficiency & 0.95 & Annual fixed cost $(\$)$ & 8012 \\
\hline Power (hp) & 350 & Operating cost $(\$ / \mathrm{hr})$ & 74.09 \\
\hline Hours per year & 600 & Purchase price & 154,899 \\
\hline Total cost $(\$ / \mathrm{hr})$ & 112.61 & Hours per day & 14 \\
\hline Annual fixed cost (\$) & 7192.62 & & \\
\hline Operating cost $(\$ / \mathrm{hr})$ & 100.63 & Stinger - Bale wrapper & \\
\hline Purchase price & 133,186 & Bales wrapped per hour & 60 \\
\hline Biomass loss & 0.02 & Mass per bale & 0.5 \\
\hline Storage loss factor & 0.50 & Wrap material $\$$ per bale & 2.45 \\
\hline Daily shift (hr/day) & 12 & Efficiency & 0.8 \\
\hline \multirow[t]{2}{*}{ Base Yield } & 2.5 & Horsepower (hp) & 20 \\
\hline & & Hours per year & 500 \\
\hline Loader - Bale & & Total cost $(\$ / \mathrm{hr})$ & 27.24 \\
\hline Number of bales per load & 2 & Annual fixed cost (\$) & 2075 \\
\hline Weight of each bale (dt) & 0.5 & Operating cost $(\$ / \mathrm{hr})$ & 23.09 \\
\hline Weight of load & 1 & Purchase price & 38,327 \\
\hline
\end{tabular}




\begin{tabular}{|c|c|c|c|}
\hline Loading time per load (min) & 0.5 & Biomass loss & 0.005 \\
\hline Unloading time per load (min) & 0.2 & Storage loss factor & 0.35 \\
\hline Efficiency & 0.75 & Number of machines & 25 \\
\hline Horsepower (hp) & 120 & Daily shift (hr/day) & 14 \\
\hline Hours per year & 1000 & Storage - dirt pad & \\
\hline Total cost $(\$ / \mathrm{hr})$ & 65.78 & Square footage per $\mathrm{dt}$ & 31.25 \\
\hline Annual fixed cost (\$) & 3431 & Fixed cost $\left(\$ / \mathrm{ft}^{2} /\right.$ year $)$ & 0.08 \\
\hline Operating cost $(\$ / \mathrm{hr})$ & 62.35 & Dirt Pad Purchase cost $\left(\$ / \mathrm{ft}^{2}\right)$ & 0.71 \\
\hline Purchase price & 66,511 & Dirt pad variable cost & 0.00 \\
\hline Biomass loss & 0 & Biomass loss & 0.25 \\
\hline Loader - Bucket & & Truck - Flat bed & \\
\hline Volume of bucket $\mathrm{ft}^{3}\left(5^{\prime} \times 5^{\prime} \times 5^{\prime}\right)$ & 125 & Number of bales per truck & 28 \\
\hline Load time (min) & 0.3 & Travel speed full (mph) & 40 \\
\hline Unload time (min) & 0.16 & Travel speed empty (mph) & 45 \\
\hline Efficiency & 0.8 & Efficiency traveling & 0.75 \\
\hline Horsepower (hp) & 300 & Weigh and inspect, unload (min) & 7 \\
\hline Hours per year & 2000 & Power (hp) & 550 \\
\hline Total cost $(\$ / \mathrm{hr})$ & 125.38 & Hours per year & 10,000 \\
\hline Annual fixed cost (\$) & 14,130 & Total cost $(\$ / \mathrm{hr})$ & 35.05 \\
\hline Operating cost $(\$ / \mathrm{hr})$ & 118.32 & Annual fixed cost (\$) & 26,078 \\
\hline Purchase price & 288,851 & Operating cost $(\$ / \mathrm{hr})$ & 30.10 \\
\hline Biomass loss & 0 & Purchase price & 149,255 \\
\hline Daily shift (hr/day) & 14 & Biomass loss & 0.005 \\
\hline Load Density $\left(\mathrm{lb} / \mathrm{ft}^{3}\right)$ & 4 & Loss Factor & 0.01 \\
\hline Load Mass (dt) & 0.25 & Daily shift (hr/day) & 12 \\
\hline Combine - Self Propelled & & Storage - Paved pad & \\
\hline Grain storage capacity (bu) & 350 & Square footage per $\mathrm{dt}$ & 20.83 \\
\hline Header width $(\mathrm{ft})$ & 15 & Fixed cost $\left(\$ / \mathrm{ft}^{2} /\right.$ year $)$ & 0.32 \\
\hline Average speed (mph) & 2.5 & Paved pad purchase $\left(\$ / \mathrm{ft}^{2}\right)$ & 2.74 \\
\hline Efficiency (fraction) & 0.75 & Paved pad variable cost & 0 \\
\hline Power (hp) & 290 & Biomass loss & 0.05 \\
\hline Unload rate (bu/hr) & 5000 & Storage - 3 days $(\mathrm{dt})$ & 7286 \\
\hline Hours per year & 600 & & \\
\hline Total cost $(\$ / \mathrm{hr})$ & 170.43 & & \\
\hline Annual fixed cost (\$) & 11,738 & & \\
\hline Operating cost $(\$ / \mathrm{hr})$ & 150.87 & & \\
\hline
\end{tabular}




\section{APPENDIX B}

Weather input during corn harvest in Des Moines, IA (The EXCEL Worksheet IBSAL Weather lists the data sequentially for 365 days)

\begin{tabular}{|c|c|c|c|c|c|c|c|c|c|c|c|}
\hline $\begin{array}{l}\text { Day } \\
\text { no. }\end{array}$ & $\begin{array}{c}\mathbf{T} \\
\left({ }^{\circ} \mathbf{C}\right)\end{array}$ & $\begin{array}{l}\text { Snow } \\
(\mathbf{m m})\end{array}$ & $\begin{array}{c}\text { RH } \\
\text { (decimal) }\end{array}$ & $\begin{array}{c}\text { Evapor- } \\
\text { ation } \\
(\mathrm{mm})\end{array}$ & $\begin{array}{l}\text { Precip- } \\
\text { itation } \\
(\mathbf{m m})\end{array}$ & Days & $\begin{array}{c}\mathbf{T} \\
\left({ }^{\circ} \mathbf{C}\right)\end{array}$ & $\begin{array}{l}\text { Snow } \\
(\mathbf{m m})\end{array}$ & $\underset{\text { (decimal) }}{\mathbf{R H}}$ & $\begin{array}{c}\text { Evapor- } \\
\text { ation } \\
(\mathbf{m m})\end{array}$ & $\begin{array}{c}\text { Precip- } \\
\text { itation } \\
(\mathbf{m m})\end{array}$ \\
\hline 245 & 21.7 & 0 & 0.59 & 10.5 & 3.3 & 287 & 22.7 & 0 & 0.79 & 9.4 & 4.7 \\
\hline 246 & 22.7 & 0 & 0.70 & 7.7 & 4.2 & 288 & 23.9 & 0 & 0.71 & 15.7 & 4.5 \\
\hline 247 & 14.2 & 0 & 0.76 & 5.3 & 2.8 & 289 & 21.8 & 0 & 0.67 & 14.4 & 3.8 \\
\hline 248 & 13.4 & 0 & 0.60 & 4.1 & 2.1 & 290 & 10.4 & 0 & 0.80 & 5.7 & 2.4 \\
\hline 249 & 15.8 & 0 & 0.61 & 6.7 & 2.5 & 291 & 7.5 & 0 & 0.70 & 5.4 & 1.8 \\
\hline 250 & 19.4 & 0 & 0.77 & 6.0 & 3.9 & 292 & 8.1 & 0 & 0.67 & 3.5 & 1.7 \\
\hline 251 & 18.5 & 0 & 0.89 & 2.8 & 4.1 & 293 & 10.0 & 0 & 0.65 & 4.8 & 1.9 \\
\hline 252 & 13.3 & 0 & 0.88 & 2.8 & 3.0 & 294 & 14.9 & 0 & 0.61 & 9.8 & 2.4 \\
\hline 253 & 13.1 & 0 & 0.70 & 6.8 & 2.4 & 295 & 10.0 & 0 & 0.56 & 9.7 & 1.7 \\
\hline 254 & 19.4 & 0 & 0.69 & 8.7 & 3.5 & 296 & 10.0 & 0 & 0.61 & 6.2 & 1.8 \\
\hline 255 & 26.4 & 0 & 0.71 & 14.0 & 5.2 & 297 & 3.5 & 0 & 0.69 & 3.4 & 1.4 \\
\hline 256 & 25.3 & 0 & 0.67 & 13.8 & 4.8 & 298 & 4.4 & 0 & 0.69 & 2.5 & 1.4 \\
\hline 257 & 21.1 & 0 & 0.59 & 9.6 & 3.3 & 299 & 10.6 & 0 & 0.63 & 7.4 & 1.8 \\
\hline 258 & 22.9 & 0 & 0.69 & 6.0 & 4.3 & 300 & 5.6 & 0 & 0.68 & 7.2 & 1.5 \\
\hline 259 & 20.4 & 0 & 0.72 & 5.6 & 3.8 & 301 & 2.8 & 0 & 0.66 & 3.6 & 1.3 \\
\hline 260 & 17.4 & 0 & 0.54 & 8.8 & 2.4 & 302 & 6.0 & 0 & 0.62 & 4.0 & 1.4 \\
\hline 261 & 18.0 & 0 & 0.54 & 8.9 & 2.5 & 303 & 10.2 & 0 & 0.63 & 7.3 & 1.9 \\
\hline 262 & 13.7 & 0 & 0.47 & 10.2 & 1.8 & 304 & 19.3 & 0 & 0.62 & 14.4 & 3.1 \\
\hline 263 & 11.2 & 0 & 0.48 & 3.3 & 1.6 & 305 & 14.2 & 0 & 0.82 & 3.6 & 3.0 \\
\hline 264 & 15.5 & 0 & 0.52 & 9.7 & 2.2 & 306 & 8.7 & 0 & 0.83 & 2.6 & 2.2 \\
\hline 265 & 16.2 & 0 & 0.66 & 5.8 & 2.7 & 307 & 5.2 & 0 & 0.76 & 3.2 & 1.7 \\
\hline 266 & 16.6 & 0 & 0.65 & 7.7 & 2.8 & 308 & 3.7 & 0 & 0.72 & 2.6 & 1.4 \\
\hline 267 & 17.3 & 0 & 0.70 & 5.5 & 3.1 & 309 & 3.3 & 0 & 0.82 & 1.7 & 1.6 \\
\hline 268 & 14.0 & 0 & 0.59 & 5.2 & 2.1 & 310 & 4.2 & 0 & 0.74 & 2.3 & 1.5 \\
\hline 269 & 15.4 & 0 & 0.56 & 7.4 & 2.2 & 311 & 7.2 & 0 & 0.73 & 3.8 & 1.8 \\
\hline 270 & 13.2 & 0 & 0.62 & 6.0 & 2.1 & 312 & 7.8 & 0 & 0.72 & 3.8 & 1.8 \\
\hline 271 & 13.0 & 0 & 0.58 & 4.4 & 2.0 & 313 & 7.2 & 0 & 0.81 & 2.3 & 2.0 \\
\hline 272 & 15.2 & 0 & 0.59 & 8.3 & 2.4 & 314 & 8.3 & 0 & 0.92 & 1.0 & 2.4 \\
\hline 273 & 16.2 & 0 & 0.72 & 5.2 & 3.0 & 315 & 5.7 & 0 & 0.71 & 5.4 & 1.6 \\
\hline 274 & 21.2 & 0 & 0.60 & 13.9 & 3.3 & 316 & 2.2 & 0 & 0.68 & 4.2 & 1.3 \\
\hline 275 & 15.5 & 0 & 0.69 & 8.9 & 2.8 & 317 & -1.4 & 0 & 0.78 & 2.1 & 1.2 \\
\hline 276 & 7.4 & 0 & 0.59 & 6.9 & 1.5 & 318 & -2.3 & 8 & 0.67 & 3.3 & 1.0 \\
\hline 277 & 6.6 & 0 & 0.58 & 3.6 & 1.4 & 319 & 0.0 & 5 & 0.71 & 2.0 & 1.2 \\
\hline 278 & 7.6 & 0 & 0.83 & 2.9 & 2.1 & 320 & 3.8 & 0 & 0.77 & 2.1 & 1.6 \\
\hline 279 & 11.0 & 0 & 0.77 & 3.3 & 2.3 & 321 & 6.7 & 0 & 0.76 & 3.2 & 1.8 \\
\hline 280 & 12.7 & 0 & 0.70 & 6.4 & 2.3 & 322 & 7.3 & 0 & 0.84 & 2.7 & 2.1 \\
\hline 281 & 12.8 & 0 & 0.88 & 2.7 & 3.0 & 323 & 9.0 & 0 & 0.76 & 4.2 & 2.1 \\
\hline 282 & 10.9 & 0 & 0.80 & 4.8 & 2.5 & 324 & 3.7 & 0 & 0.67 & 4.6 & 1.4 \\
\hline 283 & 10.1 & 0 & 0.61 & 6.8 & 1.7 & 325 & 2.2 & 0 & 0.61 & 3.0 & 1.1 \\
\hline 284 & 13.8 & 0 & 0.65 & 8.2 & 2.4 & 326 & 9.7 & 0 & 0.61 & 6.2 & 1.8 \\
\hline 285 & 17.5 & 0 & 0.79 & 5.6 & 3.6 & 327 & 7.1 & 0 & 0.80 & 3.5 & 2.0 \\
\hline 286 & 18.6 & 0 & 0.91 & 3.1 & 4.3 & 328 & 0.3 & 0 & 0.64 & 3.9 & 1.1 \\
\hline
\end{tabular}




\section{APPENDIX C}

\section{Extracting weather data from TMY2 data files}

Access website http://rredc.nrel.gov/solar/old_data/nsrdb/tmy2/. A list of locations for which weather data is available appears.

Click on "In alphabetical order by state and city" under "TMY2 Data files in compressed format"

Click on DOS format for the city/state of your choice: e.g. Idaho Pocatello

Click "Save"

Save the *.exe file in a folder - We have saved all of the weather data related to Extend in a subfolder TMY. The file name will be the file number (e.g. "24156" in this example).

Double click on the file name "24156" and click "Run." A graphic image of the file with extension *.TM2 appears in the folder (e.g. 24156.TM2)

Launch Excel. Click "File." Open 24156.TM2 using "all files" for the file type. Click "Finish."

A worksheet full of numbers will appear with a sheet number associated with the location number (e.g. 24156). Numbers and data appear as long string rows of texts. The headings for columns for row 1 are in Table 3.1 (TMY handbook on the web) and the headings of columns for the remaining rows are in Table 3.2 (TMY handbook on the web). It is not necessary to know these headings at this time.

Double click on the Excel file "TMY.xls" provided as part of IBSAL package. TMY.xls has embedded formulas to extract data from the TMY file.

Copy the entire worksheet 24156.xls and paste on Sheet1 of TMY.xls. A total of 8760 rows of hourly data will be copied. Sheet2 of TMY.xls will extract the data automatically using worksheet Macros. This is done automatically.

Place TMY.xls file in the same folder as the Extend program Weather.mox. Launch "Weather.mox." The program reads the hourly data in Sheet 2 of TMY.xls, sums or averages the data over 24 hours, and writes the results on Sheet3 of TMY.xls. The worksheet calculates daily evaporation and precipitation rates. The data then are arranged and copied onto the sheet "arrange."

Copy the entire worksheet arrange to the "IBSAL weather" worksheet in IBSAL.xls.

Duplicate TMY.xls and give the name of the location for which the date has been prepared (e.g. Pocatello.xls). 


\section{APPENDIX D}

\section{Extracting data for progress of corn grain harvest}

Launch http://www.nass.usda.gov/

Under Quick Stats (Agricultural Statistics Data base) choose "US \& State - Crops", Click button "Go"

Under step 1, select data type, scroll down, and mark "Crop Progress"

Under step 2, select data items, scroll down, and mark "Corn All"

Under step 3, select "year", chose the year or years of interest (e.g. From 2007 to 2007 interval 1).

Under step 4, select location scroll down to the state of interest and mark the state (e.g. Iowa), click

"Add" and the state's name appears in the Location(s) Selected box.

Click on button "Get Data" - Progress data appears on the screen

At the bottom of the screen click on Download CSV (units in a separate file) -The CSV file appears on the screen. Double click on the CSV file and view the Excel sheet with the progress of harvest.

Copy the week number and progress of harvest (for the specific year 2007 or an average for the past 5 years) on an Excel sheet.

The worksheet IBSAL Weather of the input file IBSAL.xls, columns A and B from Row 370 to Row 421 is filled with sequence numbers 1 to 52 (for 52 weeks). The corresponding column B is filled with 0's. Replace 0's with the percent harvested extracted from the NASS data for the corresponding weeks. For example Row 405 Column A is 36 (week 36), Column B is 4 (4\% harvested). All rows (from 405 on) are filled with percent harvest. After entering the maximum percent, the remaining rows to 421 (week 52) will have 0's in column B.

IBSAL automatically reads the week number of progress of harvest. 


\section{APPENDIX E}

\section{Running IBSAL}

If using Industry version 6.xx of the Extend Simulation language:

- Place the supplied IBSAL program in a folder. Name the folder IBSAL (or any other name)

- Place IBSAL.xls in the same folder as the program file.

- Launch Extend

- Open the file from the File menu

- Run the program

- Output is printed on the Output worksheet of IBSAL.xls

- Input parameters can be changed on the various worksheets (e.g. Farm Input, Transport Input) in IBSAL.xls

- Make sure to save the changes to the spreadsheet before executing Extend

- The model can run with animation. Click "Run" on the menu bar, click "Show Animation," and then click "Run Simulation." The program execution can speed up or slow down by clicking on the rabbit (fast) or turtle (slow). Uncheck Show Animation to return to normal (and a much speedier) run.

If Extend simulation language is not available on the computer:

- Download the IBSAL program and store it in a folder. Name the folder IBSAL (or any other name)

- Download "IBSAL.xls" and place it in folder IBSAL (the same folder in which the IBSAL program is filed)

- Download Extend PLAYER form the website www.Imaginethatinc.com. Place the Extend PLAYER in the Folder IBSAL

- Double Click Extend PLAYER

- Load the IBSAL model, click "Run" on the menu bar and choose "Run Simulation"

- Input parameters can be changed on the various worksheets in IBSAL.xls

- Make sure to save or check mark the changes to the spreadsheet before executing the Extend

- The model can run with animation. Click "Run" on menu bar, click "Show Animation," and then click "Run Simulation." The program execution can speed up or slow down by clicking on the rabbit (fast) or turtle (slow). Uncheck Show Animation to return to normal (and a much speedier) run. 